\title{
Global chemical weathering dominated by continental arcs since the mid-Paleozoic
}

Thomas M. Gernon ${ }^{\mathrm{a}, *}$, Thea K. Hincks ${ }^{\mathrm{a}}$, Andrew S. Merdith ${ }^{\mathrm{b}, \mathrm{c}}$, Eelco J. Rohling ${ }^{\mathrm{d}, \mathrm{a}}$, Martin R. Palmer ${ }^{\mathrm{a}}$, Gavin L. Foster ${ }^{\mathrm{a}}$, Clément

P. Bataille ${ }^{\mathrm{e}}$, R. Dietmar Müller ${ }^{\mathrm{f}}$

\author{
${ }^{a}$ School of Ocean E Earth Science, University of Southampton, Southampton SO14 3ZH, UK \\ ${ }^{b}$ Laboratoire de Géologie, Université of Lyon 1, France \\ ${ }^{c}$ School of Earth and Environment, University of Leeds, Leeds LS2 9JT, UK \\ ${ }^{d}$ Research School of Earth Sciences, The Australian National University, Canberra, Australia \\ ${ }^{e}$ Earth and Environmental Sciences, University of Ottawa, Ottawa, ON K1N, Canada \\ ${ }^{f}$ EarthByte Group, School of Geosciences, The University of Sydney, Australia
}

Earth's plate tectonic activity regulates the carbon cycle, and hence, climate, via volcanic outgassing and silicate-rock weathering. Mountain building, arc-continent collisions, and clustering of continents in the tropics have all been invoked as controlling the weathering flux, with arcs also acting as a major contributor of carbon dioxide $\left(\mathrm{CO}_{2}\right)$ to the atmosphere. However, these processes have largely been considered in isolation when in reality they are all tightly coupled. To properly account for interactions between these processes, and the inherent multi-million-year time lags at play in the Earth system, we need to characterise their complex interdependencies. Here we analyse these interdependencies over the past 400 million years, using a Bayesian network to identify primary relationships, time lags and drivers of the global chemical weathering signal. We find that the length of continental volcanic arcs-the fastest-eroding surface features on Earth-exerts the strongest control on global chemical weathering fluxes. We propose that the rapid drawdown of $\mathrm{CO}_{2}$ tied to arc weathering stabilises surface temperatures over geological time, contrary to the widely held view that this stability is achieved mainly by a delicate balance between weathering of the seafloor and the continental interiors.

Weathering of Earth's surface regulates climate over geological timescales $\left(\sim 1-10\right.$ million years, Myr) ${ }^{1,2,3,4,5}$. When atmospheric $\mathrm{CO}_{2}$ concentrations are high and temperatures elevated, these conditions lead to ocean acidification and an intensified hydrologic cycle with increased evaporation, precipitation and runoff $^{1}$. These conditions give rise to enhanced weathering of silicate minerals and $\mathrm{CO}_{2}$ drawdown. Conversely, reduced silicate weathering reduces $\mathrm{CO}_{2}$ drawdown under cold climates, promoting warming. This 'thermostat' stabilises surface temperatures through time ${ }^{6}$. During the Phanerozoic (541-0 million years ago, Ma), the periodic onset of icehouse conditions has variously been attributed to enhanced weathering rates associated with mountain building ${ }^{4,7}$, reductions in continental arc magmatism $^{8}$, and uplift of oceanic crust during arc-continent collisions ${ }^{9}$. Rather than occurring in isolation, these global tectonic processes are inextricably linked and the resulting collinearity - coupled with unknown time lags_ obscures each process's individual contribution to global weathering fluxes. These issues have thus far severely limited our understanding of the first-order drivers of Earth's weathering fluxes.

\section{Deep-time data mining}

To address this problem, we constructed a deep-time Bayesian Network (BN), a class of probabilistic graphical

${ }^{*}$ Corresponding author: Thomas.Gernon@noc.soton.ac.uk model that represents a set of variables (nodes) and their conditional dependencies (see Methods). This approach-widely applied in machine learning — can be used to quantify the strength of influence of individual processes on an outcome of interest (e.g., a chemical signal in seawater). Our BN uses data mining to systematically quantify the strength of the relationships between key geological variables and the chemical weathering flux to identify primary drivers and lags. To perform the analysis, we use UNINET, a software package for uncertainty analysis and high dimensional dependence modelling. UNINET has proven capability for analysing complex data, and evaluating geological relationships and temporal dependencies ${ }^{16}$. We focus on the past $400 \mathrm{Myr}$, when key predictors of weathering flux such as crustal distribution, seafloor production rates ${ }^{10}$ and atmospheric $\mathrm{CO}_{2}{ }^{11}$ are generally well constrained (Fig. 1). This period was also chosen because (1) it captures the assembly and breakup of the supercontinent Pangaea (Fig. 1a), stable from 320 to $200 \mathrm{Ma}$ (Fig. 1f); and (2) the four main lineages of vascular plants had already proliferated on land by 400 $\mathrm{Ma}^{17}$, meaning we do not expect the interval to encompass a step change in terrestrial weathering tied to soil-plant biogeochemical cycles. We compiled geospatial datasets using paleogeographic reconstruction from the open-source plate tectonic software GPlates ${ }^{18}$, processed in $R$ (Methods), to produce a diverse set of time series that capture times of key global tectonic changes (Fig. 1). Parameters include: continental arc length ${ }^{13}$; 
climate state (characterised by latitudinal extent of continental ice ${ }^{9}$ and atmospheric $\mathrm{CO}_{2}$ concentration ${ }^{11}$ ); suture zone length as a proxy for arc-continent collisions ${ }^{9}$; the spatial extent of large igneous provinces (LIPs) ${ }^{19}$; seafloor production rates; and continental fragmentation and dispersal (Fig. 1a, 1f).

We used variations in strontium isotope ratios in seawater $\left(\left({ }^{87} \mathrm{Sr} /{ }^{86} \mathrm{Sr}\right)_{s w}\right)$ derived from marine carbonates ${ }^{14}$ as a proxy for global chemical weathering through time, and calculated a moving average using a $\pm 0.25 \mathrm{Myr}$ window (Fig. 1g). Given the large contrast in ${ }^{87} \mathrm{Sr} /{ }^{86} \mathrm{Sr}$ between radiogenic continents and unradiogenic oceanic crust ${ }^{20},\left({ }^{87} \mathrm{Sr} /{ }^{86} \mathrm{Sr}\right)_{s w}$ is thought to represent a globally integrated balance in weathering flux from continental surfaces and the seafloor ${ }^{14,20,21}$. We tested this assertion by constructing a network to explore the relationship between $\left({ }^{87} \mathrm{Sr} /{ }^{86} \mathrm{Sr}\right)_{s w}$ and partial pressure of atmospheric carbon dioxide $\left(p \mathrm{CO}_{2}\right)$ since $400 \mathrm{Ma}^{11}$. This analysis reveals a clear relationship between $\left({ }^{87} \mathrm{Sr} /{ }^{86} \mathrm{Sr}\right)_{s w}$ and $p \mathrm{CO}_{2}$ (empirical correlation $=$ -0.57 ) at lag 0, which decreases with increasing lags (Extended Data Fig. 1), confirming that they are coupled ${ }^{4}$. However, as there are clearly secondary controls on $\left({ }^{87} \mathrm{Sr} /{ }^{86} \mathrm{Sr}\right)_{s w}$, and some uncertainty in the $\mathrm{CO}_{2}$ record used ${ }^{11}$, the relationship is not straightforward; this is a key justification for analysing what drives these variations through time. We present our results in terms of $\left({ }^{87} \mathrm{Sr} /{ }^{86} \mathrm{Sr}\right)_{s w}$ - the standard framework-but also test the sensitivity of our model to radioactive decay of ${ }^{87} \mathrm{Rb}$ (to ${ }^{87} \mathrm{Sr}$ ) in the crust through time ${ }^{15}$.

\section{Building an Earth network}

Despite progress in linking variations in $\left({ }^{87} \mathrm{Sr} /{ }^{86} \mathrm{Sr}\right)_{s w}$ to geodynamic and paleogeographic factors ${ }^{22}$, it is unclear how processes combine to drive $\left({ }^{87} \mathrm{Sr} /{ }^{86} \mathrm{Sr}\right)_{s w}$ variations. We constructed the network (Methods) with nodes for $\left({ }^{87} \mathrm{Sr} /{ }^{86} \mathrm{Sr}\right)_{s w}$ and twelve predictor variables (Extended Data Fig. 2; Supplementary Data File S1), with lags from 0 to 50 Myr. We present three correlation measures that summarise the relationships between the variables and $\left({ }^{87} \mathrm{Sr} /{ }^{86} \mathrm{Sr}\right)_{s w}$ (Figs. 2-4). First, the empirical rank correlation $\left(\mathrm{C}_{E m p}\right.$, the Spearman Rank correlation) is a non-parametric measure of the relationship between two variables. Although informative, this does not account for autocorrelation, or the joint influence of other variables. Second, the $\mathrm{BN}$ rank correlation $\left(\mathrm{C}_{B N}\right)$ is the modelled representation of the empirical rank correlation. In an ideal case (i.e., a perfect model) this would be equal to $\mathrm{C}_{E m p}$. Third, the conditional rank correlation $\left(\mathrm{C}_{\text {Cond }}\right)$ is the rank correlation between two variables conditional on any other parent variables (accounting for the effect of all nodes at shorter lags, and higher up in the network hierarchy; Methods).

We construct our network by starting with the variable with the highest empirical rank correlation with $\left({ }^{87} \mathrm{Sr} /{ }^{86} \mathrm{Sr}\right)_{s w}$ at lag 0 , and systematically search the set of predictor variables to find maximum values of $\mathrm{C}_{\text {Cond }}$ at increasing lags (each 2.5 Myr windows) up to 50 Myr (Methods). A variable is added to the network if its conditional correlation exceeds a confidence interval threshold (dependent on the number of original data points). The conditional correlation removes the influence of variables higher in the network hierarchy (and at shorter lags), and provides a measure of the additional information each subsequent lagged variable provides in explaining $\left({ }^{87} \mathrm{Sr} /{ }^{86} \mathrm{Sr}\right)_{s w}$ variation (Fig. 4; Extended Data Figs. 3-4). This approach is based on the method for partial autocorrelation, and efficiently accounts for multiple joint dependencies and lags (Methods). Whilst our focus below is on $\mathrm{C}_{\text {Cond }}$, for context we also provide $\mathrm{C}_{E m p}$ and $\mathrm{C}_{B N}$ (Fig. 4).

\section{Identification of chemical weathering drivers}

We find that the length of continental volcanic $\operatorname{arcs}^{13}$ (Fig. 1c), where oceanic lithosphere is subducted beneath continental lithosphere ${ }^{8}$, is most strongly correlated with $\left({ }^{87} \mathrm{Sr} /{ }^{86} \mathrm{Sr}\right)_{s w}$ $\left(\mathrm{C}_{\text {Emp }}=-0.79 ; \mathrm{C}_{\text {Cond }}=-0.7\right.$; Figs. $\left.2,3 \mathrm{a}, 4 \mathrm{a}\right)$, increasing when we correct for crustal radioactive decay of ${ }^{87} \mathrm{Rb}$ (ref. ${ }^{15} ; \mathrm{C}_{E m p}$ $=-0.82$; Fig. 2; Extended Data Table 2). This strong relationship (Figs. 2, 3a) suggests that periods of increased continental arc volcanism have favoured unradiogenic seawater compositions, and vice versa. Today, the global continental arc system is $\sim 14,000 \mathrm{~km}$ long ${ }^{13}$, and includes regions such as the Alaska Peninsula, the Cascades and the Andean Volcanic Belt (Extended Data Fig. 5). The global arc system was three times longer $(\sim 37,500 \mathrm{~km})$ during the Mesozoic (Fig. 1c), reflecting a sharp increase in seafloor production (Figs. 1c-d). The ocean chemical response to changing arc extent is rapid, peaking in $<0.5$ Myr (Fig. 4a). Before exploring the importance of these observations, we need to quantitatively evaluate how other processes combine to drive $\left({ }^{87} \mathrm{Sr} /{ }^{86} \mathrm{Sr}\right)_{s w}$.

Terrestrial weathering fluxes are highly sensitive to crustal deformation ${ }^{1,4,6,5,7}$. It has been suggested that arc-continent collisions in the tropics-where volcanic island arcs are obducted onto continents forming ophiolite complexes-gave rise to enhanced weathering of (ultra-) mafic lithologies and $\mathrm{CO}_{2}$ drawdown, driving Phanerozoic glaciations ${ }^{9,23}$. Weathering of ultramafic lithologies on this scale should reduce $\left({ }^{87} \mathrm{Sr} /{ }^{86} \mathrm{Sr}\right)_{s w}$, so the correlation should be negative, reflecting unradiogenic inputs to oceans. To evaluate this, we incorporate suture length data ${ }^{9}$ into our network (Fig. 1e; Extended Data Fig. $6)$. The empirical correlation between active suture length and $\left({ }^{87} \mathrm{Sr} /{ }^{86} \mathrm{Sr}\right)_{s w}$ is strong and positive. Accounting for other dominant processes (i.e., continental arc length), this reduces, leaving a peak $\mathrm{C}_{\text {Cond }}=0.47$ at lag 0 (Fig. 4b). Given that we find consistently positive correlations between suture length and $\left({ }^{87} \mathrm{Sr} /{ }^{86} \mathrm{Sr}\right)_{s w}$ (Fig. 4b), we infer that arc-continent collisions promote enhanced weathering of radiogenic continental material via orogenesis and erosion ${ }^{4,7}$, rather than predominantly unradiogenic ultramafics as suggested before ${ }^{9,23}$. Our results are consistent with the conventional uplift-weathering hypothesis ${ }^{4}$ and also help explain the reported link between arccontinent collisions and glaciations ${ }^{9}$. Increasing suture length appears to drive enhanced weathering of continental material, promoting $\mathrm{CO}_{2}$ consumption and cooling.

Chemical weathering is also sensitive to continental fragmentation, which increases the reach of oceanic moisture into continental interiors ${ }^{24}$, but the timescales and impacts are 
highly uncertain. To address this, we consider geospatial attributes of continents through time (Methods). Using the footprint defined by continent-ocean boundaries ${ }^{10}$, we computed the continental perimeter/area ratio ${ }^{25,26}$ —a quantitative measure of crustal fragmentation (Fig. 1f). We find that the correlation between continental fragmentation and $\left({ }^{87} \mathrm{Sr} /{ }^{86} \mathrm{Sr}\right)_{s w}$ is moderate to low (maximum $\mathrm{C}_{\text {Cond }}=0.31$ ), and positive, consistent with enhanced weathering of radiogenic crust during plate tectonic fragmentation. The peak $\mathrm{C}_{\text {Cond }}$ at time lags of $\sim 12.5-$ $15 \mathrm{Myr}$ (Fig. 4c) is commensurate with typical timescales of rift-to-drift transitions and delayed basin connectivity following continental breakup ${ }^{27}$. Accounting for lags of this order will be crucial to correct interpretation of associations between tectonic fragmentation and marine biodiversity ${ }^{28}$.

High temperatures and precipitation usually favour high weathering rates in tropical regions ${ }^{9,24}$. It has thus been hypothesised that a high proportion of continental landmasses within the tropics could strongly influence global weathering ${ }^{24}$. We test this by quantifying continental area within the tropical latitudinal bands (we test both $\pm 20^{\circ}$ and $\pm 10^{\circ}$ of the equator) at 1 Myr intervals (Fig. 1f; Extended Data Fig. 7), and integrate this in our network. The land surface area within the tropics has increased over 400-0 Ma (Fig. 1f), but makes a negligible contribution to weathering fluxes from the continental surface (Extended Data Fig. 3). This could be due to development of deep, indurated soil profiles in tropical drainage basins that lead to very low (transport-limited) weathering intensity ${ }^{29}$. Similarly, the spatial extent of LIPs through time ${ }^{19}$ is only very weakly related to $\left({ }^{87} \mathrm{Sr} /{ }^{86} \mathrm{Sr}\right)_{s w}$ (Extended Data Fig. 3), possibly because they are typically flat lying rather than mountainous terrains. This suggests that environmental perturbations associated with LIPs are most likely due to changes in volcanic $\mathrm{CO}_{2}$ fluxes ${ }^{30}$ rather than enhanced weathering of mafic lithologies.

It is well established that seafloor basalt alteration ${ }^{31}$ and hydrothermal venting decrease $\left({ }^{87} \mathrm{Sr} /{ }^{86} \mathrm{Sr}\right)_{s w}$ (i.e. toward midocean ridge basalt [MORB] mantle ${ }^{87} \mathrm{Sr} /{ }^{86} \mathrm{Sr} \simeq 0.7035$; ref. ${ }^{21}$ ). Therefore, $\left({ }^{87} \mathrm{Sr} /{ }^{86} \mathrm{Sr}\right)_{s w}$ is expected to scale inversely with seafloor production rate (Fig. 1d), which we calculate as the product of ridge length and spreading rate (Extended Data Fig. 8 ), adapting an existing plate model ${ }^{26}$. We find that seafloor production rates are negatively correlated with $\left({ }^{87} \mathrm{Sr} /{ }^{86} \mathrm{Sr}\right)_{s w}$ at short lags (Fig. 4d), reflecting the effects of early high temperature alteration of basalts along ridge axes ${ }^{32}$. The seafloor weathering contribution becomes negligible $\sim 15-20 \mathrm{Myr}$ after emplacement, suggesting that seafloor is not releasing unradiogenic Sr appreciably after this time. This is strikingly consistent with hydrothermal models ${ }^{33}$ and observations of secondary minerals in ocean crust ${ }^{34,35}$, which indicate that $\sim 70-80 \%$ of fluid flux occurs in seafloor within $20 \mathrm{Myr}$ of formation. We find that radiogenic continental weathering sources dominate the $\left({ }^{87} \mathrm{Sr} /{ }^{86} \mathrm{Sr}\right)_{s w}$ signal at lags $>20 \mathrm{Myr}$, explaining the switch to a positive correlation (Fig. 4d).

Glacial intensity is also known to influence $\left({ }^{87} \mathrm{Sr} /{ }^{86} \mathrm{Sr}\right)_{s w}{ }^{36}$. Investigating the effect of continental ice coverage, we find a strong empirical correlation between latitudinal extent of ice sheets (Fig. 1b) (as a proxy for the severity of glaciation and global climate $\left.{ }^{9}\right)$ and $\left({ }^{87} \mathrm{Sr} /{ }^{86} \mathrm{Sr}\right)_{s w}(-0.72$; Figs. $3 \mathrm{~b}$, 4e), sup- porting the notion that glaciations cause intensified weathering of continental crust ${ }^{20,36,37,38}$. This is likely due to preferential weathering of radiogenic minerals like biotite in comminuted rock flour characteristic of glaciated catchments ${ }^{37,38}$. The conditional correlation is low due to collinearity between ice extent, and arc and suture lengths. Observations suggest that weathering influences atmospheric $\mathrm{CO}_{2}$ concentration ${ }^{11}$ (Fig. 1f; Extended Data Fig. 1), but also provide evidence for a feedback whereby $\mathrm{CO}_{2}$ influences weathering (negative $\mathrm{C}_{E m p}=-0.58$ where $\left({ }^{87} \mathrm{Sr} /{ }^{86} \mathrm{Sr}\right)_{s w}$ lags $\mathrm{CO}_{2}$ by $0.5-2.5 \mathrm{Myr}$, in Fig. 4f). A weak, but statistically significant positive $\mathrm{C}_{\text {Cond }}$ between $\mathrm{CO}_{2}$ and $\left({ }^{87} \mathrm{Sr} /{ }^{86} \mathrm{Sr}\right)_{s w}$ at lags $>10 \mathrm{Myr}$ (Fig. 4f; Extended Data Figs. $3 \mathrm{f}$ and $4 \mathrm{f}$ ) suggests a weak negative carbonate-silicate feedback operating over tens of millions of years. This appears to be a secondary effect.

\section{Unpicking uncertainty}

To determine how input uncertainties could affect results, we simulated 1,000 variant time series for each input parameter, and repeated the $\mathrm{BN}$ analysis using this alternative input data set (Methods). Where available, we used existing uncertainty estimates (e.g., for $p \mathrm{CO}_{2}$ and continental arc length), and simulated uncertainty for other key variables using the best existing knowledge (Extended Data Fig. 2). The analysis reveals that when uncertainty envelopes are considered, the strongest correlations with $\left({ }^{87} \mathrm{Sr} /{ }^{86} \mathrm{Sr}\right)_{s w}$ remain largely unchanged (Extended Data Figs. 3-4), with very small differences between the BN and empirical correlations for the original and variant inputs (Extended Data Table 1; Supplementary Data File S3).

\section{Central role for volcanic arc weathering}

This analysis supports our overall conclusion that continental volcanic arc length exerts the strongest influence on global weathering fluxes during greenhouse intervals. This is consistent with regional studies ${ }^{39,40}$ and the observation that chemical weathering of island arcs dominates the oceanic Sr budget today $^{41}$, and may even have contributed to Neogene cooling ${ }^{42}$. We might expect that the variation of the island arc source over time would be similar to the continental arc source because both are ultimately dependent on spreading rates. However, we do not have a sufficiently extensive or accurate record of island arc lengths to test this hypothesis. However, if we assume that the global length of subduction zones is a crude proxy for oceanic island arc length, the observed relatively weak conditional correlations (Extended Data Fig. 3g) suggest that volcanic island arcs are unlikely to be a first-order driver of the weathering signal over geological timescales in contrast to continental arcs. The latter are an important contributor to the atmospheric $\mathrm{CO}_{2}$ inventory, owing to a propensity for decarbonation reactions in the continental lithosphere ${ }^{8}$. The strongly negative correlation between continental arc length and $\left({ }^{87} \mathrm{Sr} /{ }^{86} \mathrm{Sr}\right)_{s w}$ (Figs. 2, 3a, $4 a)$ is consistent with the hypothesis that their formation and spatial extent governs icehouse-greenhouse transitions ${ }^{8}$.

The high $\mathrm{CO}_{2}$ outgassing flux and greenhouse conditions associated with extensive continental $\operatorname{arcs}^{8}$ favour intensified 
chemical weathering ${ }^{1,5,6}$. Today, continental volcanic arcs are among the highest topographic - and fastest eroding-surface features on Earth ${ }^{39}$, supplying Ca-Mg silicate weathering products to the ocean over tens of millions of years ${ }^{40}$. Hydrothermal activity maximises water-rock interactions, which, given the enhanced orographic precipitation typical in these regions, results in extreme chemical denudation rates ${ }^{43,44}$. For example, the present-day Andes (Extended Data Fig. 5) dominates dissolved ion fluxes to the Amazon River ${ }^{45}$, fuelling Earth's greatest offshore river plume. Today, continental arcs are predominantly unradiogenic (Extended Data Fig. 5), with mean ${ }^{87} \mathrm{Sr} /{ }^{86} \mathrm{Sr}$ values of $0.7044(\mathrm{~N}=5,498$; median $=0.704$, mode $=$ $0.7035)$, only slightly higher than typical MORB and ocean island basalts ${ }^{46}$. Thus, prolonged cycles of arc assembly, erosion and weathering ${ }^{39,40}$ likely drove seawater toward the unradiogenic compositions we observe (Figs. 2-4). Greenhouse conditions linked to extensive $\operatorname{arcs}^{8}$ should promote increased bottom water temperatures and enhanced seafloor weathering ${ }^{47}$, further reducing $\left({ }^{87} \mathrm{Sr} /{ }^{86} \mathrm{Sr}\right)_{s w}$.

Continental volcanic arcs are predisposed to acidintermediate magmatism, favouring zircon production ${ }^{48}$. The interpretation that continental arcs drive global chemical weathering fluxes (Fig. 2) is therefore consistent with an observed increase in detrital zircon abundance during greenhouse intervals ${ }^{8}$. The latter implicates increased transport and weathering of arc detritus to ocean basins when continental arcs are longest. Our analysis confirms that the ${ }^{87} \mathrm{Sr} /{ }^{86} \mathrm{Sr}$ of zircon-bearing igneous rocks strongly correlates with $\left({ }^{87} \mathrm{Sr} /{ }^{86} \mathrm{Sr}\right)_{s w}$ over the past $400 \mathrm{Myr}$ (Extended Data Table 2), suggesting that global chemical weathering is tightly coupled to the composition of continental igneous lithologies ${ }^{15}$. The correlation between igneous ${ }^{87} \mathrm{Sr} /{ }^{86} \mathrm{Sr}$ and $\left({ }^{87} \mathrm{Sr} /{ }^{86} \mathrm{Sr}\right)_{s w}$ is highest $^{15}$ when arc systems are longest ${ }^{13}$. It is therefore probable that the length of continental arcs drives $\left({ }^{87} \mathrm{Sr} /{ }^{86} \mathrm{Sr}\right)_{s w}$ via the proportional availability of weatherable igneous catchments. This finding draws specific attention to the rock compositions (i.e., calc-alkaline) and climate conditions (predominantly highland and tropical-humid) that offer the best potential for accelerated $\mathrm{CO}_{2}$ drawdown in enhanced weathering schemes designed to counteract current global climate change ${ }^{49}$.

To summarise, we have developed a data mining approach based on conditional probability estimation, to disentangle complex interdependencies between solid Earth, hydrosphere, and atmospheric processes, over the past 400 million years. This approach has significant potential to aid interpretation of complex Earth data exhibiting high dimensional dependency on different spatial and temporal scales.

It is widely accepted that continental arcs modulate atmospheric $\mathrm{CO}_{2}$ levels ${ }^{8,50}$ and represent a major agent of crustal growth through post-Archean Earth history via arc accretion processes ${ }^{39}$. Our analysis indicates that arcs have also dominated global chemical weathering fluxes, which determine the Sr isotopic composition of seawater, $\left({ }^{87} \mathrm{Sr} /{ }^{86} \mathrm{Sr}\right)_{s w}$, over the past $400 \mathrm{Myr}$. This revises conventional concepts that $\left({ }^{87} \mathrm{Sr} /{ }^{86} \mathrm{Sr}\right)_{s w}$ is driven by competition between weathering of the seafloor and continental interiors. Arc weathering causes reduction in $\left({ }^{87} \mathrm{Sr} /{ }^{86} \mathrm{Sr}\right)_{s w}$ while continental weathering causes increases in $\left({ }^{87} \mathrm{Sr} /{ }^{86} \mathrm{Sr}\right)_{s w}$. Thus, our findings of arc dominance in weathering help explain enigmatic low $\left({ }^{87} \mathrm{Sr} /{ }^{86} \mathrm{Sr}\right)_{s w}$ during greenhouse climates, where the higher temperatures should according to conventional concepts have promoted greater continental crust weathering ${ }^{6}$, driving increased $\left({ }^{87} \mathrm{Sr} /{ }^{86} \mathrm{Sr}\right)_{s w}$.

Our results indicate that continental arcs provide a selfregulating thermostat, gradually removing atmospheric $\mathrm{CO}_{2}$ via rock weathering reactions that offset their more rapid high volcanic $\mathrm{CO}_{2}$ outgassing fluxes. Conversely, when continental arc extent reduces, global $\mathrm{CO}_{2}$ emissions decrease, arc weathering slows down, and continental ice sheets become the principal agent of physical and chemical weathering, driving increased $\left({ }^{87} \mathrm{Sr} /{ }^{86} \mathrm{Sr}\right)_{s w}$. Through this regulation of atmospheric $\mathrm{CO}_{2}$ levels over geological timescales, continental volcanic arcs played a central role in maintaining habitability over the course of Earth history even in the face of dramatic external drivers.

\section{Online content}

Any methods, additional references, Nature Research reporting summaries, source data, extended data, supplementary information, acknowledgements, peer review information; details of author contributions and competing interests; and statements of data and code availability are available at https://doi.org/10.1038/s12345-111-2222-3.

\section{References}

1. L. R. Kump, S. L. Brantley, and M. A. Arthur. Chemical weathering, atmospheric $\mathrm{CO}_{2}$, and climate. Annual Review of Earth and Planetary Sciences, 28(1):611-667, 2000.

2. J. F. Kasting. The Goldilocks planet? How silicate weathering maintains Earth "just right". Elements, 15(4):235-240, 2019.

3. D. E. Penman, J. K. Caves Rugenstein, D. E. Ibarra, and M. J. Winnick. Silicate weathering as a feedback and forcing in Earth's climate and carbon cycle. Earth-Science Reviews, 209:103298, 2020.

4. M. E. Raymo and W. F. Ruddiman. Tectonic forcing of late Cenozoic climate. Nature, 359(6391):117-122, 1992.

5. R. A. Berner and E. K. Berner. Silicate weathering and climate. In William F. Ruddiman, editor, Tectonic Uplift and Climate Change, pages 353-365. Springer US, Boston, MA, 1997.

6. J. C. G. Walker, P. B. Hays, and J. F. Kasting. A negative feedback mechanism for the long-term stabilization of Earth's surface temperature. Journal of Geophysical Research: Oceans, 86(C10):9776-9782, 1981.

7. J. M. Edmond. Himalayan tectonics, weathering processes, and the strontium isotope record in marine limestones. Science, 258(5088):1594, 1992.

8. N. R. McKenzie, B. K. Horton, S. E. Loomis, D. F. Stockli, N. J. Planavsky, and C.-T. A. Lee. Continental arc volcanism as the principal driver of icehouse-greenhouse variability. Science, 352(6284):444, 2016.

9. F. A. Macdonald, N. L. Swanson-Hysell, Y. Park, L. Lisiecki, and O. Jagoutz. Arc-continent collisions in the tropics set Earth's climate state. Science, 364(6436):181-184, 2019.

10. K. J. Matthews, K. T. Maloney, S. Zahirovic, S. E. Williams, M. Seton, and R. D. Müller. Global plate boundary evolution and kinematics since the late Paleozoic. Global and Planetary Change, 146:226-250, 2016.

11. G. L. Foster, D. L. Royer, and D. J. Lunt. Future climate forcing potentially without precedent in the last 420 million years. Nature Communications, 8:14845, 2017.

12. C. R. Witkowski, J. W. H. Weijers, B. Blais, S. Schouten, and J. S. Sinninghe Damsté. Molecular fossils from phytoplankton reveal secular $\mathrm{PCO}_{2}$ trend over the Phanerozoic. Science Advances, 4(11):eaat4556, 2018. 
13. W. Cao, C.-T. A. Lee, and J. S. Lackey. Episodic nature of continental arc activity since $750 \mathrm{Ma}$ : A global compilation. Earth and Planetary Science Letters, 461:85-95, 2017.

14. J. Veizer, D. Ala, K. Azmy, P. Bruckschen, D. Buhl, F. Bruhn, G. A. F. Carden, A. Diener, S. Ebneth, Y. Godderis, T. Jasper, C. Korte, F. Pawellek, O. G. Podlaha, and H. Strauss. ${ }^{87} \mathrm{Sr} /{ }^{86} \mathrm{Sr}, \delta^{13} \mathrm{C}$ and $\delta^{18} \mathrm{O}$ evolution of Phanerozoic seawater. Chemical Geology, 161(1):59-88, 1999.

15. C. P. Bataille, A. Willis, X. Yang, and X.-M. Liu. Continental igneous rock composition: A major control of past global chemical weathering. Science Advances, 3(3):e1602183, 2017.

16. T. Hincks, W. Aspinall, R. Cooke, and T. Gernon. Oklahoma's induced seismicity strongly linked to wastewater injection depth. Science, 359(6381):1251, 2018.

17. J. L. Morris, M. N. Puttick, J. W. Clark, D. Edwards, P. Kenrick, S. Pressel, C. H. Wellman, Z. Yang, H. Schneider, and P. C. J. Donoghue. The timescale of early land plant evolution. Proceedings of the National Academy of Sciences, 115(10):E2274, 2018.

18. R. D. Müller, J. Cannon, X. Qin, R. J. Watson, M. Gurnis, S. Williams, T. Pfaffelmoser, M. Seton, S. H. J. Russell, and S. Zahirovic. GPlates: Building a virtual Earth through deep time. Geochemistry, Geophysics, Geosystems, 19(7):2243-2261, 2018.

19. L. Johansson, S. Zahirovic, and R. D. Müller. The interplay between the eruption and weathering of large igneous provinces and the deep-time carbon cycle. Geophysical Research Letters, 45(11):5380-5389, 2018.

20. B. Peucker-Ehrenbrink and G. J. Fiske. A continental perspective of the seawater ${ }^{87} \mathrm{Sr} /{ }^{86} \mathrm{Sr}$ record: A review. Chemical Geology, 510:140-165, 2019.

21. H. Elderfield and A. Schultz. Mid-ocean ridge hydrothermal fluxes and the chemical composition of the ocean. Annual Review of Earth and Planetary Sciences, 24(1):191-224, 1996.

22. C. Vérard, C. Hochard, P. O. Baumgartner, G. M. Stampfli, and M. Liu Geodynamic evolution of the Earth over the Phanerozoic: Plate tectonic activity and palaeoclimatic indicators. Journal of Palaeogeography, 4(2):167-188, 2015.

23. O. Jagoutz, F. A. Macdonald, and L. Royden. Low-latitude arc-continent collision as a driver for global cooling. Proceedings of the National Academy of Sciences, 113(18):4935, 2016.

24. Y. Donnadieu, Y. Goddéris, G. Ramstein, A. Nédélec, and J. Meert. A 'snowball Earth' climate triggered by continental break-up through changes in runoff. Nature, 428(6980):303-306, 2004.

25. J.-P. Cogné and E. Humler. Global scale patterns of continental fragmentation: Wilson's cycles as a constraint for long-term sea-level changes. Earth and Planetary Science Letters, 273(3):251-259, 2008.

26. A. S. Merdith, S. E. Williams, S. Brune, A. S. Collins, and R. D. Müller. Rift and plate boundary evolution across two supercontinent cycles. Global and Planetary Change, 173:1-14, 2019.

27. R. Granot and J. Dyment. The Cretaceous opening of the South Atlantic Ocean. Earth and Planetary Science Letters, 414:156-163, 2015.

28. J.-x. Fan, S.-z. Shen, D. H. Erwin, P. M. Sadler, N. MacLeod, Q.-m. Cheng, X.-d. Hou, J. Yang, X.-d. Wang, Y. Wang, H. Zhang, X. Chen, G.-x. Li, Y.-c. Zhang, Y.-k. Shi, D.-x. Yuan, Q. Chen, L.-n. Zhang, C. Li, and Y.-y. Zhao. A high-resolution summary of Cambrian to Early Triassic marine invertebrate biodiversity. Science, 367(6475):272, 2020.

29. J. Hartmann, N. Moosdorf, R. Lauerwald, M. Hinderer, and A. J. West. Global chemical weathering and associated P-release - The role of lithology, temperature and soil properties. Chemical Geology, 363:145-163, 2014

30. N. R. McKenzie and H. Jiang. Earth's outgassing and climatic transitions: The slow burn towards environmental "catastrophes"? Elements, 15:325330, 2019.

31. S. R. Hart, A. J. Erlank, and E. J. D. Kable. Sea floor basalt alteration: Some chemical and $\mathrm{Sr}$ isotopic effects. Contributions to Mineralogy and Petrology, 44(3):219-230, 1974

32. M. J. Mottl and C. G. Wheat. Hydrothermal circulation through midocean ridge flanks: Fluxes of heat and magnesium. Geochimica et Cosmochimica Acta, 58(10):2225-2237, 1994.

33. R. D. Müller, A. Dutkiewicz, M. Seton, and C. Gaina. Seawater chemistry driven by supercontinent assembly, breakup, and dispersal. Geology, 41(8):907-910, 2013.

34. R. M. Coggon, D. A. H. Teagle, C. E. Smith-Duque, J. C. Alt, and M. J.
Cooper. Reconstructing past seawater $\mathrm{Mg} / \mathrm{Ca}$ and $\mathrm{Sr} / \mathrm{Ca}$ from mid-ocean ridge flank calcium carbonate veins. Science, 327(5969):1114, 2010.

35. E. Booij, W. E. Gallahan, and H. Staudigel. Ion-exchange experiments and $\mathrm{Rb} / \mathrm{Sr}$ dating on celadonites from the Troodos ophiolite, Cyprus. Chemical Geology, 126(2):155-167, 1995

36. J. D. Blum and Y. Erel. A silicate weathering mechanism linking increases in marine ${ }^{87} \mathrm{Sr} /{ }^{86} \mathrm{Sr}$ with global glaciation. Nature, 373(6513):415-418, 1995.

37. S. Prestrud Anderson, J. I. Drever, and N. F. Humphrey. Chemical weathering in glacial environments. Geology, 25(5):399-402, 1997.

38. D. Vance, D. A. H. Teagle, and G. L. Foster. Variable Quaternary chemical weathering fluxes and imbalances in marine geochemical budgets. Nature, 458(7237):493-496, 2009.

39. C.-T. A. Lee, S. Thurner, S. Paterson, and W. Cao. The rise and fall of continental arcs: Interplays between magmatism, uplift, weathering, and climate. Earth and Planetary Science Letters, 425:105-119, 2015.

40. H. Jiang and C.-T. A. Lee. On the role of chemical weathering of continental arcs in long-term climate regulation: A case study of the Peninsular Ranges batholith, California (USA). Earth and Planetary Science Letters, 525:115733, 2019.

41. C. J. Allègre, P. Louvat, J. Gaillardet, L. Meynadier, S. Rad, and F. Capmas. The fundamental role of island arc weathering in the oceanic $\mathrm{Sr}$ isotope budget. Earth and Planetary Science Letters, 292(1):51-56, 2010.

42. Y. Park, P. Maffre, Y. Goddéris, F. A. Macdonald, E. S. C. Anttila, and N. L. Swanson-Hysell. Emergence of the Southeast Asian islands as a driver for Neogene cooling. Proceedings of the National Academy of Sciences, 117(41):25319, 2020.

43. A. J. West, A. Galy, and M. Bickle. Tectonic and climatic controls on silicate weathering. Earth and Planetary Science Letters, 235(1):211228, 2005.

44. J. Gaillardet, P. Louvat, and E. Lajeunesse. Rivers from volcanic island arcs: The subduction weathering factory. Applied Geochemistry, 26:S350-S353, 2011.

45. M. E. McClain and R. J. Naiman. Andean influences on the biogeochemistry and ecology of the Amazon River. BioScience, 58(4):325-338, 2008.

46. R. K. O'Nions, P. J. Hamilton, and N. M. Evensen. Variations in ${ }^{143} \mathrm{Nd} /{ }^{144} \mathrm{Nd}$ and ${ }^{87} \mathrm{Sr} /{ }^{86} \mathrm{Sr}$ ratios in oceanic basalts. Earth and Planetary Science Letters, 34(1):13-22, 1977.

47. O. V. Brady and S. R. Gíslason. Seafloor weathering controls on atmospheric $\mathrm{CO}_{2}$ and global climate. Geochimica et Cosmochimica Acta, 61(5):965-973, 1997.

48. C.-T. A. Lee and O. Bachmann. How important is the role of crystal fractionation in making intermediate magmas? Insights from $\mathrm{Zr}$ and $\mathrm{P}$ systematics. Earth and Planetary Science Letters, 393:266-274, 2014.

49. D. J. Beerling, E. P. Kantzas, M. R. Lomas, P. Wade, R. M. Eufrasio, P. Renforth, B. Sarkar, M. G. Andrews, R. H. James, C. R. Pearce, J.-F. Mercure, H. Pollitt, P. B. Holden, N. R. Edwards, M. Khanna, L. Koh, S. Quegan, N. F. Pidgeon, I. A. Janssens, J. Hansen, and S. A. Banwart. Potential for large-scale $\mathrm{CO}_{2}$ removal via enhanced rock weathering with croplands. Nature, 583(7815):242-248, 2020.

50. E. Mason, M. Edmonds, and A. V. Turchyn. Remobilization of crustal carbon may dominate volcanic arc emissions. Science, 357(6348):290$294,2017$.

\section{Acknowledgements}

We thank Ryan McKenzie for comments that improved the manuscript. This study was supported by a Natural Environment Research Council (NERC) grant (NE/R004978/1) to T.G., which also supported T.H. and M.P. T.G. and T.H. were supported by The Alan Turing Institute under the EPSRC grant EP/N510129/1. R.D.M. was supported by the AuScope Simulation and Modelling National Research Infrastructure. A.S.M. was supported by the Deep Carbon Observatory, Richard Lounsbery Foundation and MCSA Fellowship NEOEARTH, project 893615 . C.P.B. was supported by the National Sciences and Engineering Research Council of Canada 
(Discovery Grant RGPIN-2019-05709).

\section{Author contributions}

T.G. conceived the idea, led the study, interpreted the data and prepared the manuscript and figures. T.H. performed the modeling, designed the network and carried out the analysis, with input from T.G. A.M. calculated the seafloor production rates, and both A.M. and D.M. provided support with GPlates and pyGPlates. M.P. and C.B. provided support with $\mathrm{Sr}$ isotope interpretation, and C.B. provided normalised $\mathrm{Sr}$ data. G.F. provided $\mathrm{CO}_{2}$ data and both G.F. and E.R. assisted with paleoclimate interpretation. T.G. wrote the manuscript with input from all co-authors.

\section{Competing interests:}

The authors declare no competing interests.

\section{Figure Captions}

Figure 1: Tectonic, atmospheric and ocean chemical changes over the past 410 Myr $\mid$ a, Continental distribution ${ }^{10}$ with continental landmasses shown in pink, present-day coastlines in black, and the tropics $\left( \pm 20^{\circ}\right.$ of the equator) in beige; b, atmospheric $\mathrm{CO}_{2}$ concentration (multi-proxy, black line) ${ }^{11}$, and phytane-based estimates in red $^{12}$; continental ice latitude ${ }^{9}$ is shown as the blue line (blue shaded regions denote glaciations); c, continental arc length ${ }^{13} ; \mathbf{d}$, seafloor production rates (Methods); e, suture zone lengths ${ }^{9}$; f, fragmentation index (i.e., continental perimeter/area, as black line), and total area of continents in the tropics (red line); $\mathbf{g},\left({ }^{87} \mathrm{Sr} /{ }^{86} \mathrm{Sr}\right)_{s w}$ from marine carbonates ${ }^{14}$, calculated as a $\pm 0.25 \mathrm{Myr}$ window in red; $\mathbf{h}$, normalised $\left({ }^{87} \mathrm{Sr} /{ }^{86} \mathrm{Sr}\right)_{s w}$ curve removing the signal caused by radioactive ${ }^{87} \mathrm{Rb}$ decay in the crust ${ }^{15}$. Minimum and maximum estimated uncertainties are shown in grey (and pink in $\mathbf{f}$ ); for all time series used and their uncertainty distributions, see Extended Data Fig. 2 (and Supplementary Data File S1).

Figure 2: Effects of continental arc extent on the strontium isotopic composition of seawater $\mid$ a, Normalised $\left({ }^{87} \mathrm{Sr} /{ }^{86} \mathrm{Sr}\right)_{s w}$ (using ref. ${ }^{15}$ ) versus continental arc length; the dashed vertical lines show the division between short $(<16,100 \mathrm{~km})$, intermediate $(16,100-29,300 \mathrm{~km})$, and extensive $(\geq 29,300 \mathrm{~km})$ arc systems (these divisions denote approximately equal quantiles); $\mathbf{b}$, Ranked normalised $\left({ }^{87} \mathrm{Sr} /{ }^{86} \mathrm{Sr}\right)_{s w}$ versus ranked continental arc length; note that the smallest value that occurs in the data set is ranked 1 . The ranked plot is a particularly useful way to visualise the relationship between variables, because it shows the correlation of the non-parametric form of the data; it is less sensitive to the underlying distributions of the data being analysed, or the effects of any extreme outliers.

Figure 3: Effects of continental arc extent and global ice distribution on the strontium isotopic composition of seawater a, Probability density for continental arc length ${ }^{13}$, identifying short $(<16,100 \mathrm{~km})$, intermediate $(16,100-29,300 \mathrm{~km})$, and extensive $(\geq 29,300 \mathrm{~km})$ arcs (note: these divisions denote approximately equal quantiles); the distributions show that extensive continental arc systems favour low $\left({ }^{87} \mathrm{Sr} /{ }^{86} \mathrm{Sr}\right)_{s w}$ and vice versa. b, Probability density for latitudinal ice extent, showing the $\left({ }^{87} \mathrm{Sr} /{ }^{86} \mathrm{Sr}\right)_{s w}$ during periods of low ice latitude $\left(<65^{\circ}\right)$, high ice attitude $\left(65-90^{\circ}\right)$ and no glaciation $\left(90^{\circ}\right)$. The distributions show that more extensive (severe) glaciations favour high $\left({ }^{87} \mathrm{Sr} /{ }^{86} \mathrm{Sr}\right)_{s w}$ and vice versa.

Figure 4: Simplified network showing key geological processes and correlations with seawater $\mathrm{Sr}$ | Illustration of a subset of our network, showing how six key variables (a-f) influence or lead $\left({ }^{87} \mathrm{Sr} /{ }^{86} \mathrm{Sr}\right)_{s w}$ (Extended Data Fig. 3). The plots summarise the relationships between each variable and $\left({ }^{87} \mathrm{Sr} /{ }^{86} \mathrm{Sr}\right)_{s w}$ using regular $0.5 \mathrm{Myr}$ time series, spanning the period $410 \mathrm{Ma}$ to $0.5 \mathrm{Ma}(\mathrm{n}=720$ time steps after accounting for lags). $\mathrm{C}_{E m p}, \mathrm{C}_{B N}$, and $\mathrm{C}_{C o n d}$ are computed at lags from 0 to 50 Myr in 2.5 Myr intervals. A lag of 0 means the processes occur within the same $0.5 \mathrm{Myr}$ time-step. The numbers in grey denote the highest absolute values of $\mathrm{C}_{E m p}$; if each process were considered in isolation this value could be interpreted as the dominant time lag. However, due to significant autocorrelation and joint dependence, the key drivers and their associated lags can be better identified by peak $\mathrm{C}_{\text {Cond }}$ (red). The horizontal dashed lines denote $99 \%$ confidence intervals estimated from the number of original data points for a given variable.

\section{Publisher's note:}

Springer Nature remains neutral with regard to jurisdictional claims in published maps and institutional affiliations.

(C) The Author(s), under exclusive licence to Springer Nature Limited 2021. 


\section{Methods}

\subsection{Bayesian Network analysis}

Here we outline the methodology for our Bayesian analysis. A Bayesian Network (BN) is a directed acyclic graph. It comprises a set of variables (which can represent discrete or continuous quantities) and a set of directed edges (arcs) between the variables, with the condition that the edges do not form a directed cycle. This means there are no loops (i.e., a node cannot be connected to itself) and no cycles (i.e., no path that leads from a node, via other nodes, back to itself). There is no requirement for the links to represent causal relationships. We use the UnINET COM library ${ }^{51}$ in Visual Studio $(\mathrm{C}++)^{52}$ to perform data mining on the time-series detailed in section 3.0 (below). UNINET represents the graphical model using joint normal copula (e.g., ref. ${ }^{16}$ ), allowing fast and efficient modelling of complex multivariate dependencies. The approach enables the identification of dominant correlations for a range of geophysical and geochemical variables with the strontium isotope ratio of seawater $\left({ }^{87} \mathrm{Sr} /{ }^{86} \mathrm{Sr}\right)_{s w}$ through geological time as a proxy for global chemical weathering ${ }^{14,15}$. All initial data processing and GIS analysis is performed in $\mathbf{R}^{53}$.

Our analysis considers data for the time period from $410 \mathrm{Ma}$ to $0 \mathrm{Ma}$, using regularised time-series with a time step of 0.5 Myr. These time-series are provided in Supplementary Data File S1 (Fig. 1). As many of the individual time-series are based on measurements, estimates or model values irregularly spaced in time, we interpolate to obtain regular $(0.5 \mathrm{Myr})$ time-series to match the resolution of the $\mathrm{CO}_{2}$ record used ${ }^{11}$. For cases with multiple observations in a given time interval, a moving average is applied (again with a $0.5 \mathrm{Myr}$ window). The number of original data points before interpolation (and accounting for lags) is used to estimate confidence interval thresholds $\left(\mathrm{CI}_{\text {thresh }}\right)$ for rank correlation coefficients for each of the variables with $\left({ }^{87} \mathrm{Sr} /{ }^{86} \mathrm{Sr}\right)_{s w}$. The CI (in this case the 99 percentile) threshold determines whether or not a particular lagged variable is retained in the model (described in detail in section 5.0). To investigate the potential time lags between the various processes and $\mathrm{Sr}$, we calculate average values for each of the predictor variables with lead times up to $50 \mathrm{My}$, in $2.5 \mathrm{Myr}$ intervals. A correlation at zero lag means the processes occur within the same time step (t, Myr). A lag of 2.5 corresponds to the correlation between $\mathrm{Sr}$ and the average value for a variable in the interval $\mathrm{t}-2.5$ to $\mathrm{t}-0.5 \mathrm{Myr}$ etc. as we are interested in how $\mathrm{Sr}$ lags the various geological processes. The one exception to this is Extended Data Fig. 1, where we present correlations for $\mathrm{Sr}$ leading $\mathrm{CO}_{2}$.

We also repeated the $\mathrm{BN}$ data mining using 1 Myr interval input data, and the differences in the results were negligible. We impose CI thresholds based on the original number of observations, not the length of the interpolated time-series.

\subsection{Uncertainty Analysis}

To investigate the effect of uncertainty in the original input data, we simulated 1,000 variant time series for each parameter, and used this alternative data set to test the $\mathrm{BN}$ analysis and search algorithm (see section 5.0). For each input parameter (with the exception of $p \mathrm{CO}_{2}$, where variant time series output from Foster et al. ${ }^{11}$, were used directly), we performed random sampling to generate multiple alternative time series, at the same resolution as the original data. Each simulated input time series was then interpolated to produce a regular $0.5 \mathrm{Myr}$ time series, and time lags were calculated in the same manner as for the original input data set.

In some cases, there are existing models of variability (e.g., for $\left.p \mathrm{CO}_{2}\right)^{11}$ or published error estimates (e.g., upper and lower bounds for continental arc length ${ }^{13}$ ), and we can directly apply these 'known' uncertainties. For other parameters, we have to make reasonable assumptions to characterise their uncertainty, based on existing knowledge of the individual processes or model limitations (see Section 3.2).

The $\left({ }^{87} \mathrm{Sr} /{ }^{86} \mathrm{Sr}\right)_{s w}$ and igneous $\mathrm{Sr}$ ratio were treated slightly differently to the inputs derived from tectonic reconstructions or proxy records because these curves are well established and based on several thousand individual direct measurements across the period of interest. Therefore, it is reasonable to accept that the variability present in the raw data (e.g., Fig. 1g) provides a good approximation of the 'true' uncertainty. Rather than simulating additional noise, we vary the width of the time window used to calculate a moving average.

Fundamentally, characterising the uncertainties in many of these processes (e.g., global tectonics) is complex, because the time series are of differing resolution, and the individual geological processes vary on different timescales. Some processes vary rapidly (on timescales of the order $\sim 1$ Ma or less) whereas others (e.g., subduction length) are expected to vary more slowly. In addition, there are physical grounds for autocorrelation and correlation between processes, which cannot be explicitly simulated without making many assumptions. To avoid making unjustifiable or overly complex model choices we simply use independent random sampling to make perturbations to the original data and thus simulate uncertainty. This is a cautious approach and will reduce correlation (and autocorrelation) for any given variable.

For parameters with no well-defined or widely accepted error bounds, we have attempted to strike a balance between estimating a reasonable level of uncertainty, and preserving the physical characteristics of the individual time series (i.e., the expected frequency of oscillation in time; e.g., arc length is relatively steady over 1-2 Myr, whereas atmospheric $\mathrm{CO}_{2}$ can vary more rapidly). For several parameters (see section 3.2), we applied increased uncertainty for ages older than c. 200 Ma because little oceanic lithosphere of this age is preserved today ${ }^{54}$, leading to greater uncertainty in tectonic simulations that cover the studied period from 410-200 Ma. As the BN is learned purely from the data and requires no prior assumptions about conditional dependence between nodes, it can readily be updated should new observations (or better-constrained uncertainty estimates) become available. Thus, our hypotheses are explicitly open to further scrutiny and testing using the same modelling approach.

In our primary analysis, we use a single time series for each parameter that represents the best available evidence. These inputs are all from published time series of observations, model 
simulations or proxy data. Below, we detail the process of simulating input uncertainty for each parameter in turn. These simulated time series (and associated time lags) were combined into a single input data file ( $\sim 3$ GB size, comprising 1,000 individual variant time series for 253 nodes including lags), and used to test the $\mathrm{BN}$ by:

(a) Calculating the empirical and $\mathrm{BN}$ correlations for all variables/lags and comparing the results with calculations for the original 'best estimate' input data (Extended Data Fig. $4)$;

(b) Running the $\mathrm{BN}$ node search algorithm to identify the variables/lags that provide the most information about $\left({ }^{87} \mathrm{Sr} /{ }^{86} \mathrm{Sr}\right)_{s w}$, and again comparing these results with the search using the original input data.

\subsection{Network Nodes and Uncertainty Distributions}

The principal aim of our analysis is to identify the variables that are most strongly correlated with $\left({ }^{87} \mathrm{Sr} /{ }^{86} \mathrm{Sr}\right)_{s w}$ (the "node of interest'), and at what time lags, in order to quantitatively understand the primary geological processes driving chemical weathering. We used the variation in $\left({ }^{87} \mathrm{Sr} /{ }^{86} \mathrm{Sr}\right)_{s w}$ ratios derived from marine carbonates ${ }^{14}$ (Fig. 1g).

These raw $\left({ }^{87} \mathrm{Sr} /{ }^{86} \mathrm{Sr}\right)_{s w}$ data produce an irregular time-series with around 5,900 individual data points spanning the interval from 410 to $0 \mathrm{Ma}$, with a maximum interval of $10.2 \mathrm{Myr}$. To generate a regular time-series for our 'node of interest' we took a moving average of $\left({ }^{87} \mathrm{Sr} /{ }^{86} \mathrm{Sr}\right)_{s w}$ using a rolling window of $\pm 0.25 \mathrm{Myr}$. We do not consider lagged values for $\mathrm{Sr}$ here, as we are primarily interested in identifying the processes that lead $\left({ }^{87} \mathrm{Sr} /{ }^{86} \mathrm{Sr}\right)_{s w}$. We do however present a separate analysis of the relationship between lagged $\left({ }^{87} \mathrm{Sr} /{ }^{86} \mathrm{Sr}\right)_{s w}$ and $\mathrm{CO}_{2}$ (Extended Data Fig. 1).

\section{1: Network Nodes:}

The variables investigated are:

1. Plate tectonic fragmentation: Continental areas were estimated from shapefiles generated by the open-source plate tectonic reconstruction software GPlates ${ }^{18,55}$. We used the plate tectonic reconstruction of Matthews et al. ${ }^{10}$ for extracting latitudinal and time-sensitive data for our analysis. This plate model is a synthesis of the Domeier and Torsvik ${ }^{56}$ model for the Late Palaeozoic and the Müller et al. ${ }^{57}$ model for the Mesozoic and Cenozoic. All data were extracted with the plate model in a palaeomagnetic reference frame, and the output comprises georeferenced maps of continent boundaries at 1 million year (Myr) intervals from $410 \mathrm{Ma}$ to the present.

Areas were calculated by taking continental polygons (which characterise the shape and location of all the continental landmasses) from the GPlates shapefiles ${ }^{10}$, and splitting them into 6 bands according to latitude (90$\left.20^{\circ} \mathrm{N}, 20-10^{\circ} \mathrm{N}, 10-0^{\circ} \mathrm{N}, 0-10^{\circ} \mathrm{S}, 10-20^{\circ} \mathrm{S}, 20-90^{\circ} \mathrm{S}\right)$. The Rsaga package function rsaga.intersect.polygons is used to split the continental shapes by latitude, working in
WGS84 global reference system coordinates (EPSG4326). The total continental area within each latitude band is calculated by first 'dissolving' and cleaning the polygons using the rsaga.geoprocessor function shapes-polygons, then calculating the total area using the areaPolygon function from the $\mathbf{R}$ geosphere package. Area is calculated in $\mathrm{m}^{2}$, and-accounting for the accuracy of shapefiles and the coordinate transformation from longitude/latitude-is considered accurate to approximately 2 significant figures. This is reasonable given the model uncertainty and resolution.

We measured the perimeter of continental landmasses through time using the perimeter function from the $\mathbf{R}$ geosphere package, and adapted the method of Cogné and Humler $^{25}$ and Merdith et al. ${ }^{26}$ to compute the continental perimeter/area ratio-a measure of how "fragmented" the continents are through time (Fig. 1f; Supplementary Data File S1). In contrast to ref. ${ }^{26}$ we do not apply a minimum area threshold, as for the time period we are considering, we only require the reconstructions of Matthews et al. ${ }^{10}$ and do not need to incorporate other plate models of variable spatial resolution. We do however remove 'holes' with areas $<5 \times 10^{11} \mathrm{~m}^{2}$, to eliminate the extremely narrow void spaces (slithers) that occur where adjacent continental polygons never fully join due to their geometry and resolution in the model. Leaving these 'holes' in place significantly inflates the perimeter estimate at certain time steps, and they can be clearly identified as erroneous gaps from inspection of the individual shape-files. Units of fragmentation are $\mathrm{m}^{-1}$ (perimeter/area), and are extracted at $1 \mathrm{Myr}$ intervals, then interpolated to $0.5 \mathrm{Myr}$.

2. Land surface area within the tropics $\left(a: \pm 10^{\circ}\right.$, and b: $\pm 20^{\circ}$ of the equator): The area of the continental land surface (a) within $10^{\circ}$ degrees of the equator (i.e., the tropical rain belt ${ }^{9}$ ) and (b) $\pm 20^{\circ}$ of the equator were measured as described above, again using shapefiles exported from GPlates and processed in $\mathbf{R}$. The latitudinal distribution of continental landmasses (within both $\pm 20^{\circ}$ (Fig. 1f) and $\pm 10^{\circ}$ bands) and the fractional areas of continental landmasses in the equatorial bands (i.e., area within the belt divided by the total crustal area) through time are shown in Extended Data Figure 7, and the data are available in Supplementary Data File S1. The result is a $1 \mathrm{Myr}$ interval time-series (units: $\mathrm{m}^{2}$ ), interpolated to $0.5 \mathrm{Myr}$ for the $\mathrm{BN}$ analysis.

3. Seafloor production rates: We calculated seafloor production rates as the product of ridge length and spreading rate of each discrete spreading segment (i.e., each mid ocean ridge segment separated by a transform boundary) at 1 Myr time steps, using the pyGPlates python library ${ }^{58}$. The data were extracted from the Matthews et al. ${ }^{10}$ plate model. The spreading segments were defined by obtaining the tangent to the midpoint of the spreading segment and measuring the angle between this and the great circle of the stage pole orientation (i.e., spreading direction) that passes 
through the segment midpoint (Extended Data Fig. 8). If this angle exceeds $70^{\circ}$, it is assumed to represent a spreading segment, and the full spreading rate was extracted and multiplied by the length of the segment. The sum of all segments $\times$ full spreading rate was calculated at 1 Myr intervals to give total seafloor production. Further details on this approach are provided in Extended Data Fig. 8.

A key uncertainty in the construction of seafloor production rates is that very little oceanic lithosphere older than $200 \mathrm{Ma}$ is preserved today ${ }^{54}$. However, our analysis does not concern time sensitive evolution of oceanic lithosphere (such that is required for understanding how oceanic volume changes through time, or the delivery of volatiles to trenches, for instance). Instead, we just require a measure of the volume of new crust formed through time. The global tectonic models used to estimate our seafloor production rates are underpinned by many geological constraints. For example, Atlantic-style oceans that opened during the Palaeozoic (e.g., the Mesoand Neotethys Oceans) are well constrained by rift-drift records and palaeomagnetic data, allowing a first-order estimate of ocean basin evolution, as implemented in plate models. The Panthalassa Ocean basin in the Matthews et al. ${ }^{10}$ model was constructed by Domeier and Torsvik ${ }^{56}$ to ensure that spreading rate and ridge length was sufficient to ensure convergence at all subduction zones that encircled the ocean basin. We therefore consider that-while a non-unique solution - the evolution of this ocean basin in the Palaeozoic provides a robust minimum estimate of the volume of ocean crust added to the globe over this time.

Finally, one of the implications of our analysis for the past 410 Myrs is that seafloor production rate exerts a relatively weak control on $\left({ }^{87} \mathrm{Sr} /{ }^{86} \mathrm{Sr}\right)_{s w}$ through time. To test the sensitivity of this result to the uncertainty in spreading rates prior to $200 \mathrm{Ma}$, we developed a $\mathrm{BN}$ for the past 200 Myrs, when seafloor spreading rates are much better constrained. We found that the empirical correlation between seafloor production rates and $\left({ }^{87} \mathrm{Sr} /{ }^{86} \mathrm{Sr}\right)_{s w}$ reduces even further (i.e., relative to the $410 \mathrm{Myr}$ network; from -0.28 to -0.16). This test, targeting the interval with the highest certainty, provides confidence that seafloor production rate is of secondary importance in global chemical weathering, and has been particularly weak since the early Jurassic.

The output is a 1 Myr interval time-series (units: $\mathrm{km}^{2} / \mathrm{Myr}$ ), which we interpolate to $0.5 \mathrm{Myr}$ for purposes of our analysis.

4. Continental arc length: We used a global compilation of continental volcanic arc lengths ${ }^{13}$ that is based on the spatial extent of granitoids, currently exposed at the Earth's surface, associated with continental arc magmatism. Accordingly, these estimates are independent from any plate model used in our analysis. Here, the minimum length is based on the actual (i.e., observed) extent of the surface exposure of the granitoids, and the maximum length is based on the geological interpretation of the original spatial ex- tent of the arcs (described in the Supplementary Information accompanying $\mathrm{Cao}$ et al. ${ }^{13}$ ). It must be noted that, for the present-day, these estimates omit several areas experiencing continental subduction (e.g., under Zealandia, flat slab subduction in the Andes). In most cases, the minimum and maximum lengths are equal, and in cases where these deviated we used the average length value-noting that the difference between the minimum/maximum and the average length is $<11.5 \%$ during the period of interest (Fig. 1c). The time-series (units: $\mathrm{km}$ ) is regular with a 1 Myr interval, interpolated to 0.5 Myr.

5. Suture zone length: We used a database of suture zone length that records sites of ophiolite obduction during arccontinent collisions ${ }^{9}$. Here, the suture zone lengths were estimated using the observed spatial extent of ophiolites based on published geological maps and global lithological compilations. Macdonald et al. ${ }^{9}$ reconstructed the locations of suture zones throughout the Phanerozoic using paleogeographic models. They estimated the duration of suture zone activity using the onset of ophiolite obduction (as evidenced by the first occurrence of arc exhumation), which they defined as the first appearance of ophiolitederived detritus in the foreland; and the termination of foreland deposition was taken to mark the cessation of ophiolite obduction (procedure is described in the Supplementary Information accompanying ref. ${ }^{9}$ ). Since the suture "length" in a region is maintained as long as associated sedimentary deposits are accumulating in the foreland basin", the "duration" measure of Macdonald et al. ${ }^{9}$ is considered a crude proxy for the volume of exhumed ophiolites. The time-series (units: $\mathrm{km}$ ) is regular with a 5 Myr interval, interpolated to 0.5 Myr.

6. Atmospheric $\mathrm{CO}_{2}$ concentration: We used a compilation of the partial pressure of atmospheric carbon dioxide $\left(p \mathrm{CO}_{2}\right)$ for the past $420 \mathrm{Ma}$ derived from multi-proxy measurements $(\mathrm{N}=1241$; from the literature and covering five independent techniques; ref. $\left.{ }^{11}\right)$. Foster et al. ${ }^{11}$ used a set of criteria to screen and standardise these records, and applied Monte Carlo resampling and a local polynomial regression (LOESS) fit to the resulting data series. We used the maximum probability $p \mathrm{CO}_{2}$ data from ref. ${ }^{11}$ (Supplementary Data File S1), with associated 68 and 95 percentile ranges (Fig. 1b). We note that recent phytane-based measurements ${ }^{12}$ are in good agreement with this long-term $p \mathrm{CO}_{2}$ record (Fig. 1b). The time-series from Foster et al. ${ }^{11}$ (units: ppm) is regular with a $0.5 \mathrm{Myr}$ interval.

7. Latitudinal ice extent: We used a recent compilation of the latitudinal extent of continental ice sheets (e.g., 90 $=$ no ice sheets) from Macdonald et al. ${ }^{9}$. This compilation is based on a literature review of the geological constraints on glaciation during the Phanerozoic, and the inferred paleogeographic extent of continental ice using updated age constraints (a full discussion of this database is described in the Supplementary Information accompanying ref. ${ }^{9}$ ). The time-series (units: degrees) is regular with 
a 1 Myr interval interpolated to $0.5 \mathrm{Myr}$.

8. Subduction zone length: The total length of subduction zones (including oceanic arcs) through geological time were taken from Matthews et al. ${ }^{10}$, and extracted using pyGPlates $^{58}$ at 1 Myr intervals. Spatial and temporal constraints on the distribution and extent of subduction zones are provided by geological constraints such as, for instance, ophiolites, subduction-related magmatism and the occurrence of high pressure metamorphic lithologies that are consistent with subduction processes ${ }^{59}$.

As noted by Merdith et al. ${ }^{59}$, there are some similarities in the trends of subduction zone and continental arc lengths ${ }^{13}$, lending support to these independently-derived measures. The time-series is regular at $1 \mathrm{Myr}$ intervals (units: $\mathrm{km}$ ), interpolated to $0.5 \mathrm{Myr}$.

9. Active LIP area: We used the area of Large Igneous Provinces (LIPs) actively erupting at a particular $1 \mathrm{Myr}$ time step from the compilation of Johansson et al. ${ }^{19}$. This database, which includes continental and oceanic LIPs, was compiled and digitised from the literature and their locations were reconstructed using GPlates software ${ }^{19}$. An underlying assumption of this time-series is that the LIPs were active for a total period of $3 \mathrm{Myr}$ after their accepted eruption age. The time-series is regular at $1 \mathrm{Myr}$ intervals (units: $\mathrm{km}^{2}$ ), interpolated to $0.5 \mathrm{Myr}$.

10. Weatherable LIP area in the tropics: We also use the area of LIPs (active or inactive) exposed within $15^{\circ}$ of the equator at a particular 1 Myr time step ${ }^{19}$. Johansson et al. ${ }^{19}$ applied paleogeographic reconstructions to discriminate between continental and oceanic LIPs in order to isolate exposed (continental) LIPs within the tropics. This regular time-series ( $1 \mathrm{Myr}$ interval, units: $\mathrm{km}^{2}$ ) provides a minimum estimate of LIP area through time.

11. Igneous Sr ratio: We use the ${ }^{87} \mathrm{Sr} /{ }^{86} \mathrm{Sr}$ ratio of zirconbearing igneous rocks (i-zig) over the last $400 \mathrm{Ma}$, from the compilation of Bataille et al. ${ }^{15}$ that spans $1000 \mathrm{Ma}$, to assess the relative contribution of continental igneous rock lithologies (i.e., dominantly continental volcanic arcs, the locus of zircon formation) to $\left({ }^{87} \mathrm{Sr} /{ }^{86} \mathrm{Sr}\right)_{s w}$. The authors applied a bootstrap resampling approach to correct for geographic/sampling biases in the detrital zircon record comprising 24,715 individual zircon grains. Bataille et al. ${ }^{15}$ used the relationship between the $\epsilon \mathrm{Hf}$ compositions of zircons and the $\epsilon \mathrm{Sr}$ of their igneous host rocks to estimate the secular variations in the $\left({ }^{87} \mathrm{Sr} /{ }^{86} \mathrm{Sr}\right)_{i-z i g}$ through time-reflecting the changing proportion of juvenile and reworked materials generated during orogenesis. We reran code from Bataille et al. ${ }^{15}$, using a modified smoothing window of $5 \mathrm{Myr}$, and increment and scale of 0.5 Myr (previously $10 \mathrm{Myr}$ and $1 \mathrm{Myr}$, respectively, in Bataille et al. ${ }^{15}$ ). Additionally, we applied an adaptive window (decreasing in size) for data points between 5 and $0 \mathrm{Ma}$, to enable extension of the time-series to $0.5 \mathrm{Ma}$.

\section{2: Uncertainty Distributions}

For the original input time series for the node of interest, $\left({ }^{87} \mathrm{Sr} /{ }^{86} \mathrm{Sr}\right)_{s w}$, we used a centred moving average with a window of 0.5 Myr (i.e., at each time step, $t$, we calculated the mean within the window $(\mathrm{t}-0.25)$ to $(\mathrm{t}+0.25) \mathrm{Myr})$. For the uncertainty analysis, the window for the moving average was varied from 1 to $5 \mathrm{Myr}$, by randomly sampling from a uniform distribution on the interval $[1,5]$.

We simulated input uncertainty for each of the predictor nodes (numbered as above) as follows, before finally interpolating to give a regular $0.5 \mathrm{Myr}$ time step, and calculating time lags up to $50 \mathrm{Myr}$. We generated 1,000 variant time series for each observable (and associated lags), and merged these into a single input file to perform BN learning. The simulated uncertainties for each node are shown in Extended Data Fig. 2.

1. Plate tectonic fragmentation: We consider the rift record of the last $400 \mathrm{Ma}$ to be robust because this interval only encompasses one supercontinent breakup (i.e., there is little overprint and many passive margins have not been inverted ${ }^{60}$. Here, because little oceanic lithosphere older than $200 \mathrm{Ma}$ is preserved today ${ }^{54}$, affecting the fidelity of plate models for this age, we applied increased uncertainty for ages before $200 \mathrm{Ma}$. For 410-200 Ma we applied a uniform random variation of up to $\pm 10 \%$, and a centred moving average with a 10-15 Myr window (discrete uniform sample). For 200-0 Ma, where the data confidence is greater, we applied a uniform random variation of up to $\pm 5 \%$, and a centred moving average with a 5-10 Myr window (discrete uniform sample).

2. Land surface area within the tropics (a: $\pm 10^{\circ}$, and b: $\pm \mathbf{2 0}$ of the equator): Latitude is constrained by palaeomagnetic data, the mean uncertainty of which is approximately $10 \%{ }^{61}$. For $410-200 \mathrm{Ma}$, we applied a conservative $\pm 20 \%$ random variation (uniform distribution), and a centred moving average with 10-15 Ma window (discrete uniform sample). For 200-0 Ma, we applied a $\pm 10 \%$ random variation (uniform distribution), and a centred moving average with 10-15 Ma window (discrete uniform sample).

3. Seafloor production rates: Again, seafloor production rates are uncertain because little or no in situ oceanic crust older than c. $200 \mathrm{Ma}$ is preserved ${ }^{54}$. To account for this, at each time step from 410-200 Ma, we applied a random variation up to $\pm 10 \%$, sampled from a uniform distribution, which was considered an acceptable range based on existing models of ocean basins ${ }^{54}$. We then took a centred moving average with a variable 2-5 Myr window (sampled from a discrete uniform distribution). For seafloor younger than $200 \mathrm{Ma}$, we applied $\pm 5 \%$ random variation (again using a uniform distribution), and a centred moving average with a 1-2 Myr window (discrete uniform sample). This range is in line with known errors for other parameters in the simulation, and reflects the increased uncertainty further back in time. 
4. Continental arc length: Much of the data include estimates for the minimum, maximum and mean continental arc lengths ${ }^{13}$. For cases where only a single estimate is provided (i.e., no range was specified in the published compilation) we apply an uncertainty of $\pm 10 \%$ of the published values as a reasonable approximation to the upper and lower bounds, and assume that the cited value is the mean estimate. This is a cautious but reasonable approach given that, where reported, measured uncertainty is typically of the order $\pm 10 \%$ (ref. ${ }^{13}$ ). Simulated time series were generated by sampling (at each 1 Ma time step) from a Beta distribution with the specified minimum, maximum and mean and (in the absence of any more information about the true uncertainty distribution) assuming a standard deviation of $20 \%$ of the range. The Beta distribution was chosen because it varies smoothly over a fixed interval, and appropriate shape parameters can be readily estimated given the mean, range and standard deviation.

5. Suture zone length: The published dataset ${ }^{9}$ does not include an estimate of uncertainty. However, the suture zone records are underpinned by plate simulations that become increasingly uncertain further back in time than $200 \mathrm{Ma}$ (see 1-3 above). Accordingly, at each 5 Myr time step, in the absence of uncertainty estimates, we varied the data by a randomly sampled (uniform) $\pm 10 \%$ for ages older than $200 \mathrm{Ma}$, and $\pm 5 \%$ for $200-0 \mathrm{Ma}$. Again, this range is in line with known errors for other parameters in the simulation (e.g., continental arc length), reflects increased uncertainty further back in time, and also takes into account the resolution of the original data.

6. Atmospheric $\mathrm{CO}_{2}$ concentration: We used 1,000 individual realisations of the multi-proxy $\mathrm{CO}_{2}$ time series of Foster et al. ${ }^{11}$, in which each data point was randomly varied within its age and $\mathrm{CO}_{2}$ uncertainty. Our original time series for $\mathrm{CO}_{2}$ uses $p \mathrm{CO}_{2}$ prob max from Foster et al. ${ }^{11}$ this is the modal value from their simulations at each 0.5 Myr time step.

7. Latitudinal ice extent: The temporal resolution of this data set is $\sim 1 \mathrm{Myr}$, although the spatial resolution is fairly coarse because latitude is estimated to the nearest $5^{\circ}$. We therefore chose to vary the values of both time and latitude at each step change, rather than every $1 \mathrm{Myr}$. This preserves the coarseness of the input rather than introducing artificial 'fast' (i.e., short time scale) variability, which is not present in the original data. We applied the following steps:

(i) Perturbed the time stamp: For times older than 10 Ma (where there is less certainty about timing of glaciation), we varied the time of each step change by a random amount up to $\pm 0.5 \mathrm{Myr}$, sampled from a uniform distribution.

(ii) Perturbed the latitude estimate by a random amount, sampling from a uniform distribution $\pm 2.5^{\circ}$.

(iii) Interpolated to $0.5 \mathrm{Myr}$, and calculated time lags.
8. Subduction zone length: Subduction zone length is derived from plate tectonic reconstructions, and is related to both continental arc length, and the spatial extent of arc-continental collisions (i.e., as indicated by suture zone length). We therefore followed a similar approach to that used for suture zone length (5, above), and continental arc length (4). For 410-200 Ma, we applied a (uniform) random variation to the length of up to $\pm 10 \%$. Because this is not a rapidly varying process (significant changes are expected to occur on timescales $>1 \mathrm{Myr}$ ), we then applied a centred moving average with a 5-10 Myr window (discrete uniform sample). For 200-0 Ma, where length estimates are better constrained, we applied uniform $\pm 5 \%$ random variation, and a centred moving average with a 5-10 Myr window (discrete uniform sample), again because subduction zone length is not expected to vary very rapidly.

9. Active LIP area: For 410-200 Ma, we applied a uniform random variation of up to $\pm 20 \%$ (again due to the greater uncertainty in model estimates before $200 \mathrm{Ma}$ ), and a centred moving average with a 5-10 Myr window (discrete uniform sample). For 200-0 Ma, we applied a uniform random variation of up to $\pm 10 \%$, and a centred moving average with a 1-5 Myr window (discrete uniform sample).

10. Weatherable LIP area in the tropics: Same as (9) above.

11. Igneous $\mathbf{S r}$ ratio: This time series was derived from 3,500 individual measurements spanning 410 to $0 \mathrm{Ma}$. Here we adopted the method of calculation of Bataille et al. ${ }^{15}$, but varied the window used to smooth the data from 2.5 to 7.5 Myr, sampling the window size from a uniform distribution (previously we used a fixed window of $5 \mathrm{Myr}$ ). In addition, the increment (i.e., the time step used in the calculations) was also varied by randomly sampling from a uniform distribution from 0.25 to $1.25 \mathrm{Myr}$ (previously we used a fixed increment of $0.5 \mathrm{Myr}$ ).

\subsection{Auto- and Cross-correlations}

Many of the studied variables are strongly auto-correlated and cross-correlated (e.g., due to being different proxies for the same or related processes/states). This makes it very difficult to identify dominant driving processes and their time lags. It is straightforward to compute partial autocorrelations for individual parameters - a standard approach in time-series analysis, however the multivariate case cannot always be solved. We tested whether the multivariate partial autocorrelation could be computed for our data set using an $\mathbf{R}$ implementation of the $\mathrm{PACF}^{62}$ (function acf/pacf in the stats package). This function computes the partial lag autocorrelation matrix $\mathrm{P}(\mathrm{s})$ of Heyse and $\mathrm{Wei}^{62}$ (pp 411-414 in $\mathrm{Wei}^{63}$ ), where $\mathrm{P}(\mathrm{s})$ is the autocorrelation matrix between $\mathbf{Z}_{t}$ and $\mathbf{Z}_{t+s}$ after removing the linear dependency on the vectors at intervening lags $\mathbf{Z}_{t+1}, \mathbf{Z}_{t+2} \ldots \mathbf{Z}_{t+s-1}$. The elements are normalised correlation coefficients. Based on this analysis, we concluded that the multivariate $\mathrm{PACF}^{62}$ could not successfully be computed for our data. 
To provide an alternative means of accounting for the combined effect of multiple parameters (at varying lags) on the variable of interest $\left({ }^{87} \mathrm{Sr} /{ }^{86} \mathrm{Sr}\right)_{s w}$, we developed a novel method based on conditional correlation, estimated using UNINET ${ }^{51}$. The approach we employ is similar in principle to the multivariate partial autocorrelation, but evaluates the conditional correlation for variables added iteratively to the $\mathrm{BN}$ at increasing time lags.

Code is written in $\mathrm{C}++$ and uses the UnINET Windows COM library ${ }^{51}$. UNINET ${ }^{51}$ is a software package for uncertainty analysis and dependence modelling for high dimensional distributions ${ }^{64,65}$. It is available as a standalone application, and as a Windows COM library (the UNINET Engine) enabling alternative programming interfaces, including but not limited to: $\mathbf{R}$, Matlab, and Visual Studio/C++ (used here). UNINET models empirical multivariate distributions by building a joint density function from a set of inputs (data mining). Joint dependency is represented by conditional rank correlation, using the joint normal copula ${ }^{66}$.

\subsection{Summary of the data mining algorithm}

Input data are time-series for the variable of interest $\mathbf{X}_{t}$ (which in this instance is $\left.\left({ }^{87} \mathrm{Sr} /{ }^{86} \mathrm{Sr}\right)_{s w}\right)$ and the 12 predictor variables $\mathbf{A}_{t}, \mathbf{B}_{t}, \mathbf{C}_{t}, \ldots \mathbf{L}_{t}$ (observables listed in section 3.0), plus lagged values of those variables $\mathbf{A}_{t-2.5} \ldots \mathbf{A}_{t-50}$ etc. Nodes are grouped and evaluated in order of increasing lag, giving a set of observables $\left(\mathbf{A}_{t}, \mathbf{B}_{t}, \mathbf{C}_{t}, \ldots \mathbf{L}_{t}\right)$ at lag $0 ;\left(\mathbf{A}_{t-2.5}, \mathbf{B}_{t-2.5}, \ldots\right.$ $\left.\mathbf{L}_{t-2.5}\right)$ at lag t-0.5 Myr to t-2.5 Myr etc., up to 50 Myr.

We construct the network by starting with the unlagged variable with the highest empirical correlation with $\left({ }^{87} \mathrm{Sr} /{ }^{86} \mathrm{Sr}\right)_{s w}$, then systematically search through the set of remaining predictor variables to find maximum values of conditional correlation $\left(\mathrm{C}_{\text {Cond }}\right)$ at increasing time lags. At each iteration we look for the largest $\mathrm{C}_{\text {Cond }}$ as this identifies the variable that individually provides the maximum additional information at each step. The variable with the largest $\mathrm{C}_{\text {Cond }}$ is subsequently added to the network if all of these following conditions are met:

1. Its conditional correlation $\mathrm{C}_{\text {Cond }}$ (the correlation with $\left({ }^{87} \mathrm{Sr} /{ }^{86} \mathrm{Sr}\right)_{s w}$, conditional on all other variables in the network) exceeds a specified confidence interval threshold. Here we use the $99 \%$ CI, with the threshold depending on the number of observations used to generate the timeseries for the variable in question. This results in a higher threshold for lower resolution variables.

2. The difference between the (unconditional) empirical rank correlation $\mathrm{C}_{E m p}$ and $\mathrm{BN}$ (i.e., modelled) rank correlation $\mathrm{C}_{B N}$ with $\left({ }^{87} \mathrm{Sr} /{ }^{86} \mathrm{Sr}\right)_{s w}$ is less than $30 \%$. This eliminates variables that cannot be represented accurately by the $\mathrm{BN}$ (using normal copulae) and prevents such nodes affecting the estimates of conditional dependence for subsequent nodes.

3. The variable is not highly correlated (a correlation of 0.8 or greater) with any existing variables in the network (i.e., nodes higher up in the network hierarchy). This reduces the effect of collinearity.
This procedure is repeated for each discrete time lag, resulting in the lagged variables being either added to the network (in order of decreasing conditional correlation and increasing lag, respectively), or rejected for not meeting one of the three criteria above. These steps ensure the construction of a parsimonious model where only the most informative nodes are retained. We present the calculated Empirical, BN (modelled) and Conditional (modelled) rank correlations for each variable and time lag in Figure 3 and Extended Data Figures 3-4.

The computational efficiency of UNINET means that this approach is suitable for application to large numbers (of the order hundreds to thousands) of nodes-greater than demonstrated here.

\section{1: Itemised steps to construct the network:}

1. Generate a saturated $\mathrm{BN}$ using all variables (nodes) with lag $0\left(\mathbf{A}_{t}, \mathbf{B}_{t}, \mathbf{C}_{t} \ldots \mathbf{X}_{t}\right)$ and identify the node with the largest empirical correlation $\left(\mathbf{C}_{E m p}\right)$ with the variable (node) of interest $\mathbf{X}_{t}$. This node (e.g., $\mathbf{C}_{t}$ ) individually gives the most information about $\mathbf{X}_{t}$ so it is placed first in the network hierarchy. The variable of interest $\mathbf{X}_{t}$ always remains last in the hierarchy, as we are interested in computing the probabilty of $\mathbf{X}_{t}$ given all the other observables. (NB: A saturated BN contains arcs linking every pair of nodes in the network).

2. Step through all the remaining nodes with lag $0\left(\mathbf{A}_{t} \ldots \mathbf{L}_{t}\right)$ and add them one by one, as a second "test node" in the network. Calculate the conditional rank correlation $c$ for each test node in turn e.g., $c=\mathrm{C}_{\text {Cond }}\left(\mathbf{X}_{t} \mathbf{A}_{t} \mid \mathbf{C}_{t}\right)$.

Poor fit (i.e., how well the $\mathrm{BN}$ can represent dependency with the node of interest $)$ is penalised by calculating c' $=(1-$ p)c, where $\mathrm{p}$ is a penalty value simply based on the absolute fractional difference between the empirical and $\mathrm{BN}$ correlations $\left(\mathrm{C}_{E m p}\left(\mathbf{X}_{t} \mathbf{A}_{t}\right)\right.$ and $\mathrm{C}_{B N}\left(\mathbf{X}_{t} \mathbf{A}_{t}\right)$ respectively); i.e., if these are the same, the penalty $\mathrm{p}$ is zero:

$$
\mathrm{p}=\operatorname{abs}\left(\left(\mathrm{C}_{E m p}\left(\mathbf{X}_{t} \mathbf{A}_{t}\right)-\mathrm{C}_{B N}\left(\mathbf{X}_{t} \mathbf{A}_{t}\right)\right) / \mathrm{C}_{E m p}\left(\mathbf{X}_{t} \mathbf{A}_{t}\right)\right)
$$

This prioritises inclusion of nodes that can be represented most accurately by the BN.

3. Find the node that has the largest (absolute) value c' $\left(c^{\prime}{ }_{\max }\right)$. If the conditional correlation $\mathrm{c}$ is below the specified confidence interval threshold set for this particular node, or if $p>0.3$ (the $\mathrm{BN}$ and empirical correlations differ by more than $30 \%$ ), the node is eliminated and not added to the network (in this case, move to step 5).

4. Reduce collinearity (high correlations between predictor nodes) as follows: If the node giving c' ${ }_{\text {max }}$ has not already been eliminated in step (3) calculate the empirical correlation of this node with all other nodes higher in the BN hierarchy (i.e., all nodes other than the node of interest, $\mathbf{X}_{t}$ ). If this returns an empirical correlation greater than a given threshold (in this case 0.8 ) indicating high collinearity, the node is eliminated and not added to the network. If 
the empirical correlations are all below 0.8 , add the node to the network and proceed to step (5).

5. Repeat steps (2) through (4) with all remaining lag 0 nodes, until they are all either added to, or eliminated from the network according to the steps above.

6. Repeat steps (2) through (5) using the set of nodes with lag 0.5-2.5 Myr $\left(\mathbf{A}_{t-2.5}, \mathbf{B}_{t-2.5}, \ldots \mathbf{L}_{t-2.5}\right)$ etc., up to the maximum lag (50 Myr).

Using the resulting network, we can then compute and plot the conditional rank correlation for each variable at increasing lag, having effectively removed both the effect of shorter period lags, and other more informative predictor variables (see Fig. 4; Extended Data Figs. 3-4).

Please note that an additional reference is cited in an Extended Data Figure 67.

\section{Data availability}

All data generated or analysed during this study are provided in the online version of this article (Supplementary Data Files S1-S3) and in Extended Data Tables 1-2. These data are also available to download via the figshare repository, at the following DOI addresses:

\section{S1: dx.doi.org/10.6084/m9.figshare.14877099}

S2: dx.doi.org/10.6084/m9.figshare.14877132

S3: dx.doi.org/10.6084/m9.figshare.14877162

\section{Source data}

\section{Supplementary Data File S1:}

Time-series compilation of all data used in our network, spanning the period from 410-0 Ma. This includes (a) the predictor variables, which are: continental arc length ${ }^{13}$, suture zone length ${ }^{9}$, latitudinal extent of continental ice sheets ${ }^{9}$, continental area within $20^{\circ}$ of the tropics (this study), continental area within $10^{\circ}$ of the tropics (this study), plate tectonic fragmentation index (this study), subduction zone length ${ }^{10,59}$, seafloor production rates (this study), atmospheric $p \mathrm{CO}_{2}$ (ref. ${ }^{11}$ ), area of LIPs within $15^{\circ}$ of the tropics ${ }^{19}$, eruptive area of LIPs ${ }^{19}$, ${ }^{87} \mathrm{Sr} /{ }^{86} \mathrm{Sr}$ of continental igneous lithologies ${ }^{15}$; and (b) the node of interest, $\left({ }^{87} \mathrm{Sr} /{ }^{86} \mathrm{Sr}\right)_{s w}$ (ref. $\left.{ }^{14}\right)$, as well as a normalised version accounting for radioactive decay of ${ }^{87} \mathrm{Rb}$ in the crust through geological time ${ }^{15}$. The records were interpolated to obtain a regular (1 Myr interval) time-series, and in cases where multiple values occurred within a single time stamp we used a moving average with a 1 Myr window.

\section{Supplementary Data File S2:}

Summary of the simulated time series (capturing uncertainty) for all input parameters, including the mean, median, 10th and 90th percentiles, and minimum and maximum values at $0.5 \mathrm{Ma}$ time steps (see Methods for details). The full input file with all simulated inputs is $3 \mathrm{~GB}$ in size.
Supplementary Data File S3:

$\mathrm{S} 3$ tabulates the empirical rank correlations $\left(\mathrm{C}_{E m p}\right)$ and $\mathrm{BN}$ correlations $\left(\mathrm{C}_{B N}\right)$ for all individual input parameters and lagged parameters (the predictor nodes) with $\left({ }^{87} \mathrm{Sr} /{ }^{86} \mathrm{Sr}\right.$ ) $s w$ (the node of interest). These were calculated by generating a saturated Bayesian Network with all 254 nodes (including lags), and computing $\mathrm{C}_{E m p}$ and $\mathrm{C}_{B N}$ for all predictor nodes with $\left({ }^{87} \mathrm{Sr} /{ }^{86} \mathrm{Sr}\right)_{s w}$. Correlations have been calculated using both the original ('best estimate') input data set and also the simulated data set, to evaluate the effect of input uncertainty (see Extended Data Fig. 2).

\section{Code availability}

More details on the computational methods and tools used for this study are available from the corresponding author (Thomas.Gernon@noc.soton.ac.uk) upon reasonable request.

51. Uninet software designed by the Risk and Environmental Modeling group, Delft University of Technology, developed by Dan Ababei, Lighttwist Software; https://lighttwist-software.com/uninet/.

52. Microsoft Visual Studio Technologies, Develop C and $\mathrm{C}++$ applications; https://visualstudio.microsoft.com/vs/features/cplusplus/.

53. The R Project for Statistical Computing; https://cran.r-project.org/.

54. R. D. Müller, M. Sdrolias, C. Gaina, and W. R. Roest. Age, spreading rates, and spreading asymmetry of the world's ocean crust. Geochemistry, Geophysics, Geosystems, 9(4):Q04006, 2008.

55. GPlates software for the interactive visualisation of plate-tectonics; https://www.gplates.org/.

56. M. Domeier and T. H. Torsvik. Plate tectonics in the late Paleozoic. Geoscience Frontiers, 5(3):303-350, 2014.

57. R. D. Müller, M. Seton, S. Zahirovic, S. E. Williams, K. J. Matthews, N. M. Wright, G. E. Shephard, K. T. Maloney, N. Barnett-Moore, M. Hosseinpour, D. J. Bower, and J. Cannon. Ocean basin evolution and globalscale plate reorganization events since Pangea breakup. Annual Review of Earth and Planetary Sciences, 44(1):107-138, 2016.

58. PyGPlates library for GPlates functionality using the Python programming language; https://http://www.gplates.org/docs/pygplates/.

59. A. S. Merdith, A. S. Collins, S. E. Williams, S. Pisarevsky, J. D. Foden, D. B. Archibald, M. L. Blades, B. L. Alessio, S. Armistead, D. Plavsa, C. Clark, and R. D. Müller. A full-plate global reconstruction of the Neoproterozoic. Gondwana Research, 50:84-134, 2017.

60. A. M. Celăl Şengör, Boris A. Natalin, Richard E. Ernst, and Kenneth L. Buchan. Rifts of the world, volume 352, pages 389-482. Geological Society of America, 2001.

61. T. H. Torsvik, R. Van der Voo, U. Preeden, C.1 Mac Niocaill, B. Steinberger, P. V. Doubrovine, D. J. J. van Hinsbergen, M. Domeier, C. Gaina, E. Tohver, J. G. Meert, P. J. A. McCausland, and L. R. M. Cocks. Phanerozoic polar wander, palaeogeography and dynamics. Earth-Science Reviews, 114(3):325-368, 2012.

62. J. F. Heyse and W. W. S. Wei. Modelling the advertising-sales relationship through use of multiple time series techniques. Journal of Forecasting, 4(2):165-181, 1985.

63. W. W. S. Wei. Time Series Analysis. Addison-Wesley, 1990.

64. B. Ale, L.J. Bellamy, R.M. Cooke, M. Duyvis, D. Kurowicka, P.H. Lin, O. Morales, A. Roelen, and J. Spouge. Causal Model for Air Transport Safety. Technical report, NLR Air Transport Safety Institute, 2009.

65. B. J. M. Ale, L. J. Bellamy, R. van der Boom, J. Cooper, R. M. Cooke, L. H. J. Goossens, A. R. Hale, D. Kurowicka, O. Morales, A. L. C. Roelen, and J. Spouge. Further development of a causal model for air transport safety (CATS): Building the mathematical heart. Reliability Engineering $\mathcal{E}$ System Safety, 94(9):1433-1441, 2009.

66. D. Kurowicka and R. Cooke. Uncertainty Analysis with High Dimensional Dependence Modelling. John Wiley Sons, Ltd, 2006. 
67. C. R. Stern. Active Andean volcanism: its geologic and tectonic setting. Revista Geológica de Chile, 31(2):161-206, 2004.

\section{Additional information}

Supplementary information is available for this paper at https://doi.org/10.1038/s12345-111-2222-3.

Correspondence and requests for materials should be addressed to T.G.

Reprints and permissions information is available at http://www.nature.com/reprints. 

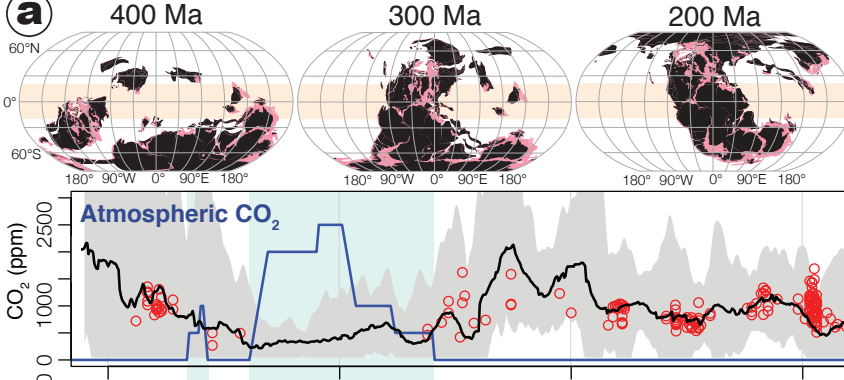

$180^{\circ} 90^{\circ} \mathrm{W} \quad 0^{\circ} \quad 90^{\circ} \mathrm{E} \quad 180^{\circ}$

$180^{\circ} 90^{\circ} \mathrm{W} \quad 0^{\circ} \quad 90^{\circ} \mathrm{E} \quad 180^{\circ}$

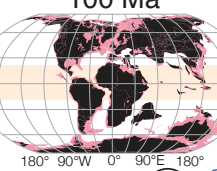

$60^{\circ} \mathrm{S}$

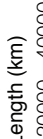

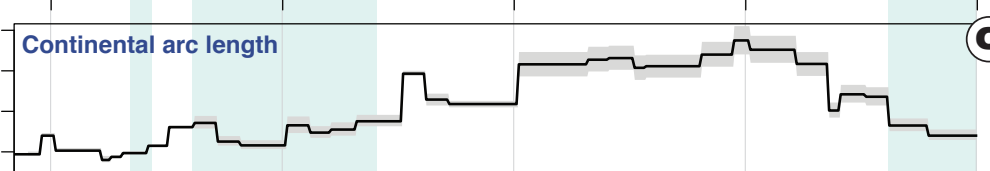

$\widetilde{1}$

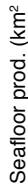

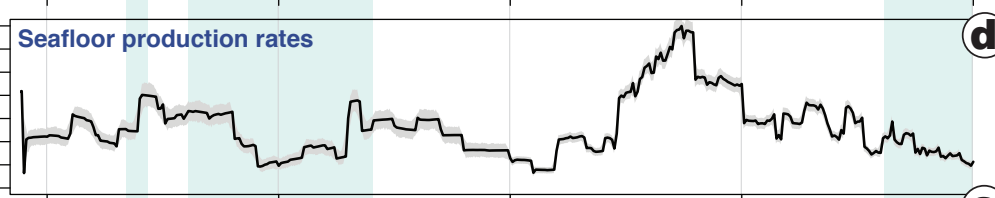

(d)

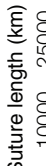

Suture zone length

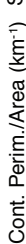

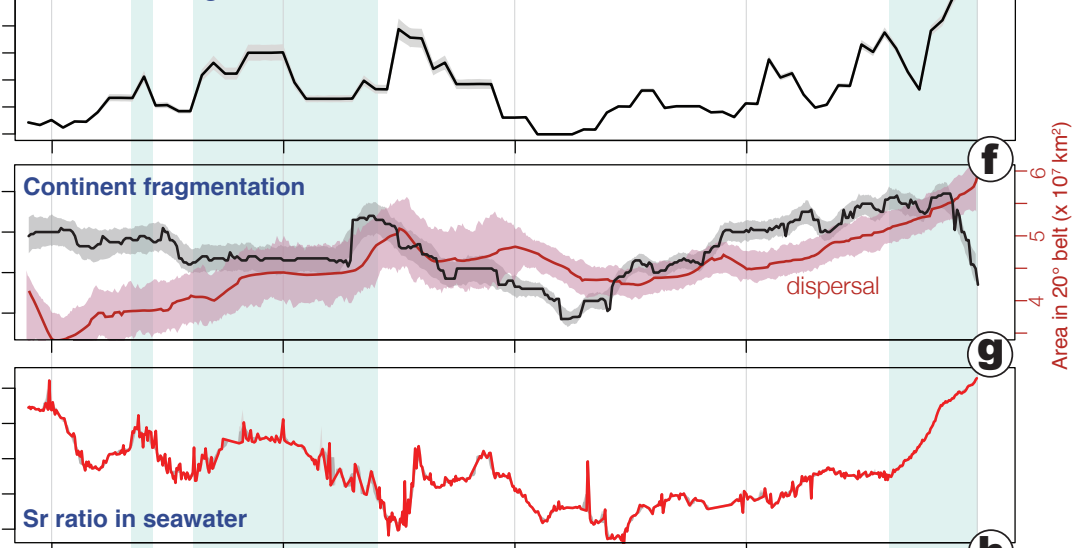

(f)

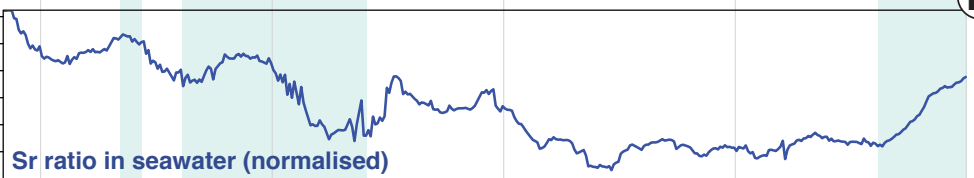

(h)

\begin{tabular}{|c|c|c|c|c|}
\hline \multicolumn{2}{|r|}{ Paleozoic } & \multicolumn{2}{|c|}{ Mesozoic } & Cenozoic \\
\hline 400 & 300 & $\begin{array}{c}200 \\
\text { Age (Ma) }\end{array}$ & 100 & \\
\hline
\end{tabular}



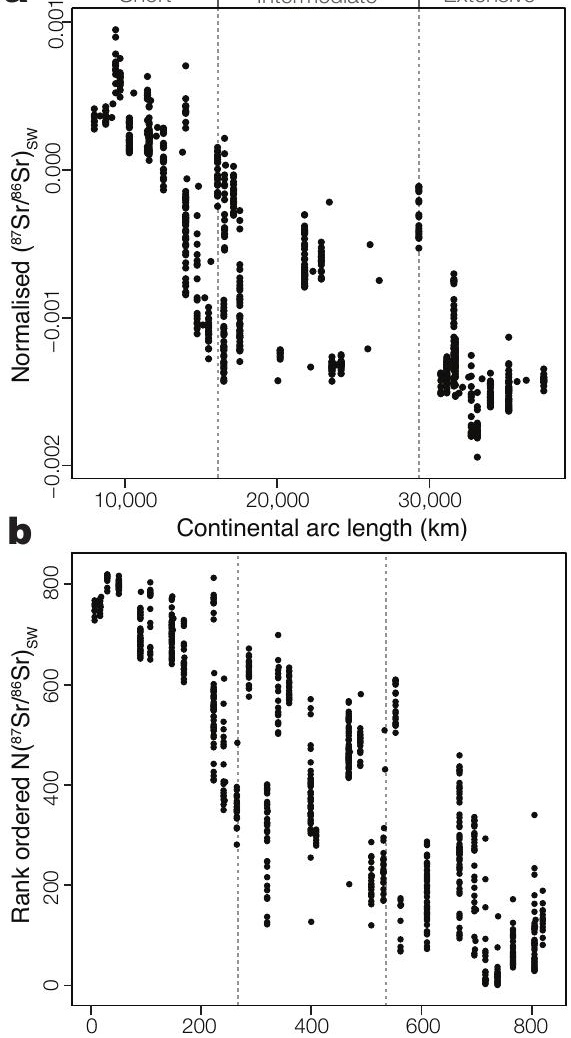

Rank ordered continental arc length 


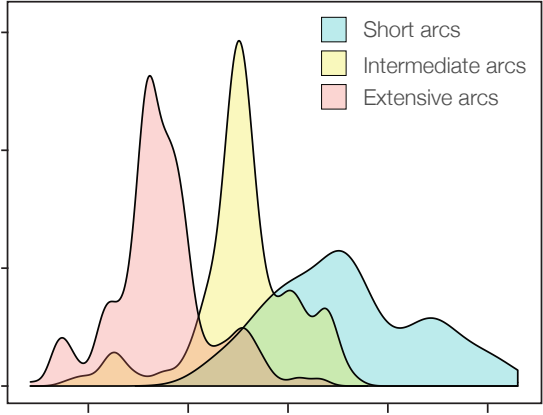

\subsection{0 \\ 0.7075 \\ 0.7080 \\ 0.7085 \\ 0.7090}

8. $\square$ Low ice latitude $\left(<65^{\circ}\right)$

$\square$ High ice latitude $\left(65-90^{\circ}\right)$

$\square$ No Glaciation

$\frac{7}{0}$

8

N

$\stackrel{8}{\circ}$

ㅇ.

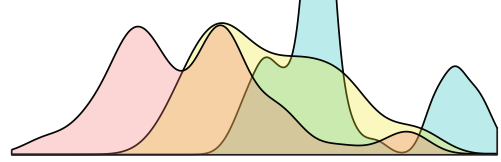

$\begin{array}{lll}0.7070 & 0.7075 & 0.7080\end{array}$

0.7085

0.7090 
a Continental arc
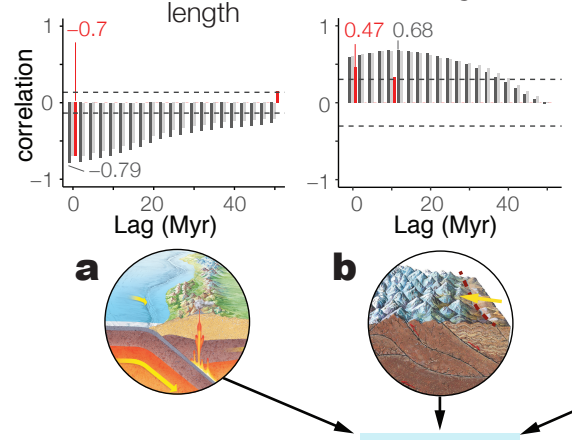

C Fragmentation

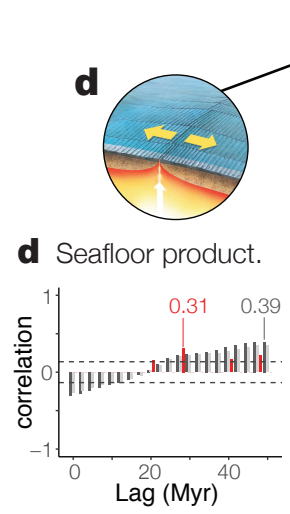

c

Empirical correlation e Ice latitude

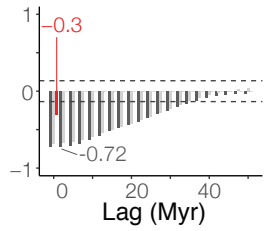

BN correlation
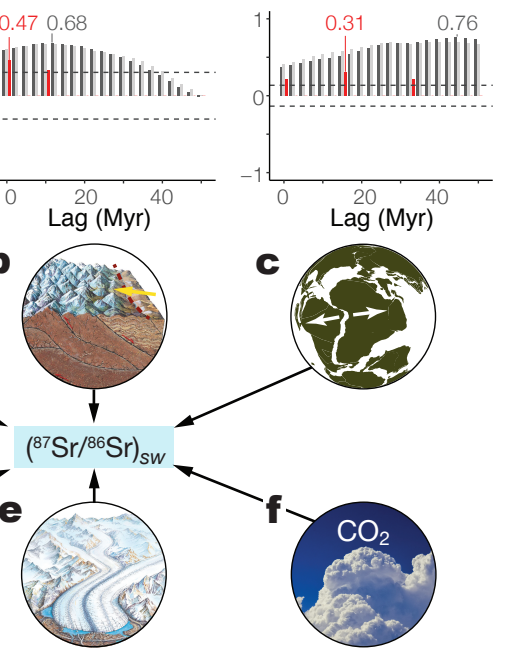

f $p \mathrm{CO}_{2}$

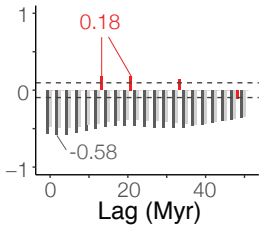

Conditional correlation 